\section{Análise da evolução urbana no entorno do estuário do Rio Cocó - Fortaleza/Ceará nos anos de 1985, 1996 e 2007}

\begin{abstract}
Resumo: Com intuito de avaliar a evolução urbana que se deu no entorno do estuário do Rio Cocó/ Fortaleza/CE e seus impactos negativos, no período entre 1985, 1996 e 2007, foi realizada uma análise multitemporal a partir de imagens TM/Landsat-5 dos respectivos anos em ambiente SIG. Foram definidas 9 unidades de uso e cobertura do solo (Área Urbana; Rio; Vegetação Natural; Planície Hipersalina; Lagoas e alagadiços; Dunas; Faixa de Praia; lagoas Interdunares Intermitentes; Bancos de Areia), que foram quantificadas e comparadas. Os resultados apresentados apontam para a necessidade de um monitoramento sistemático da expansão urbana; para identificação e controle das cargas poluentes de origem residencial e comercial; para o fomento da educação ambiental; para a ampliação do efetivo de policiais na fiscalização do Parque Ecológico e para a sua adequação ao Sistema Nacional de Unidade de Conservação - SNUC.
\end{abstract}

\section{Analysis of urban development surrounding the estuary of the River Coco - Fortaleza/Ceará in 1985, 1996 and 2007}

\footnotetext{
Abstract: In order to evaluate the urban evolution that occurred in the vicinity of the estuary of the Rio Coco/Fortaleza/ CE and its negative impacts in the period between 1985, 1996 and 2007, we performed an analysis from multitemporal images of TM/Landsat-5 respective years in a GIS environment. 9 units were defined use and land cover (Urban Area; River; Natural Vegetation; Plain hypersaline; Ponds and wetlands, dunes, beach range; Intermittent inter dune ponds; Banks of Sand), which were quantified and compared. These results suggest the need for systematic monitoring of urban sprawl, for identification and control of pollution loads sources identical and commercial to promote environmental education to expand the effective oversight of the police and the Ecological Park its suitability for the National System of Conservation Units - SNUC.
}

Eduardo Viana Freires*

Daniel Dantas Moreira Gomes**

José Antonio Beltrão Sabadia***

Cynthia Romariz Duarte*** Michael Vandesteen Silva Souto ***

* Mestre em Geologia Ambiental pela Universidade Federal do Ceará (UFC). Professor da Secretaria de Educação do Estado do Ceará (SEDUC-CE).

** Doutorando em Geologia na UFC. Professor Assistente na Universidade de Pernambuco (UPE) - Campus Garanhuns.

***Professor (a) Doutor (a) no Departamento de Geologia da UFC.

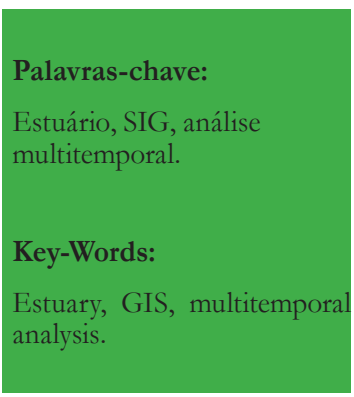




\section{Introdução}

Como a maior parte dos corpos d'água em áreas urbanas do território brasileiro, o Rio Cocó, que cruza a porção oriental da cidade de Fortaleza-Ce, é marcado por forte intervenção humana. Sem o monitoramento da expansão urbana na capital cearense por parte do poder público, houve um progressivo avanço de edificações nas áreas de várzea e nas margens do Rio que conduziram a significativas mudanças em seu quadro físico.

Ao longo de seu curso podem ser observadas obras de infraestrutura pública, como pontes e estradas, além de prédios comerciais e, sobretudo, áreas residenciais, que vão desde habitações insalubres, representadas por favelas, até aquelas fruto da especulação imobiliária que atende a pessoas de alto poder aquisitivo.

O resultado da urbanização desordenada é a supressão em diversos pontos da mata ciliar, o que vem favorecendo a erosão de suas margens com consequente assoreamento de seu leito. Pode se observar ainda que ao longo da planície de inundação, inclusive sobre o mangue, ocorrem diversos pontos de aterramentos, que se tornam necessários para edificação nesse tipo de terreno. Além disso, associado ao processo de urbanização ocorre à impermeabilização dos solos, que compromete a recarga do lençol subterrâneo e gera sérios transtornos durante o período chuvoso com os alagamentos de ruas e avenidas. A qualidade dos recursos hídricos também está comprometida a partir do lançamento de efluentes e resíduos sólidos lançados ao rio e em seus afluentes, pela população do seu entorno, sobretudo daquelas habitações que não dispõem de saneamento básico.

Todas essas mudanças não só alteram a paisagem local, como também, comprometem a biodiversidade, impossibilitam a navegação, inibem atividades recreativas, educativas e turísticas, inviabilizando, consequentemente, o desenvolvimento de práticas sustentáveis.

A situação se torna mais grave quando se considera que a vegetação que margeia o Rio faz parte de área de preservação permanente (APP) de acordo Art. 4 da Lei No 12.651, de 25 de maio de 2012. Além disso, seu trecho estuarino, que apresenta $13 \mathrm{~km}$ de extensão, faz parte do Parque Ecológico do Cocó, criado através do decreto estadual no $20.253 / 1989$, e ampliado a partir do decreto $n^{\circ} 22.587 / 1993$, totalizando uma área de 1.155,2 hectares.

Como forma de alertar sobre o agravamento dos impactos gerados ao longo do Rio Cocó, a partir das atividades humanas no decorrer dos anos, tendo em vista o grande incremento populacional na cidade, que já ultrapassou os dois milhões e meio de habitantes, o presente trabalho tem como objetivo geral analisar o processo de uso da cobertura do solo no entorno de seu estuário nos anos de 1985, 1996 e 2007, utilizando como suporte de avaliação das mudanças ocorridas as imagens do satélite TM/Landsat-5 e reconhecimento de campo integrado em ambiente SIG. Especificamente, objetivou-se gerar mapa de uso e cobertura do solo da área de estudo, na escala de 1:100.000 para cada ano de imageamento; Quantificar e mapear a evolução da Área Urbana no entorno do estuário do Rio Cocó para os períodos de 1985/2007, 1985/1996 e 1996/2007.

\section{Área de estudo}

A área de estudo localiza-se na porção Nordeste da cidade de Fortaleza, no Estado do Ceará

Geografia Ensino \& Pesquisa, v. 17, n.3, p. $153-174$, set./dez. 2013

Análise da evolução urbana no entorno do estuário do Rio Cocó - Fortaleza/Ceará... (Figura 1), e corresponde ao trecho estuarino do Rio Cocó, que cruza a região Leste da capital no sentido Sul/Norte e sofre uma acentuada inflexão em direção a sua foz no sentido Sudoeste-Leste.

O estuário está inserido no Parque Ecológico do Cocó criado pelo Governo Estadual por meio do decreto $\mathrm{n}^{\circ} 22.253$, de 05 de setembro de 1989 , e ampliado a partir do decreto $\mathrm{n}^{\circ}$ 22.587, de 08 de Junho de 1993, perfazendo uma área total de 1.155,2 hectares. Assim como o estuário, os limites do Parque Ecológico correspondem ao trecho nas proximidades da BR116 à foz do Rio Cocó. 
Pelo fato do estuário do Rio Cocó receber influência direta da urbanização verificada em seu entorno, a delimitação da área de estudo se deu a partir dos bairros localizados em suas adjacências, que são: Aerolândia, Alto da Balança, São João do Tauape, Manoel Dias Branco, Praia do Futuro II, na margem esquerda, e Jardim das Oliveiras, Salinas, Edson Queiroz e Sabiaguaba, na margem direita, conforme pode ser observado na Figura 1.

A área compreendida por esses bairros totaliza $45,20 \mathrm{Km}^{2}$ e situa-se entre as coordenadas $9.586 .747 \mathrm{~m}$ e $9.577 .318 \mathrm{~m} \mathrm{~N} ; 553.236 \mathrm{~m}$ e $566.456 \mathrm{~m} \mathrm{E}$.

Figura 1 - Mapa de localização da área de estudo.

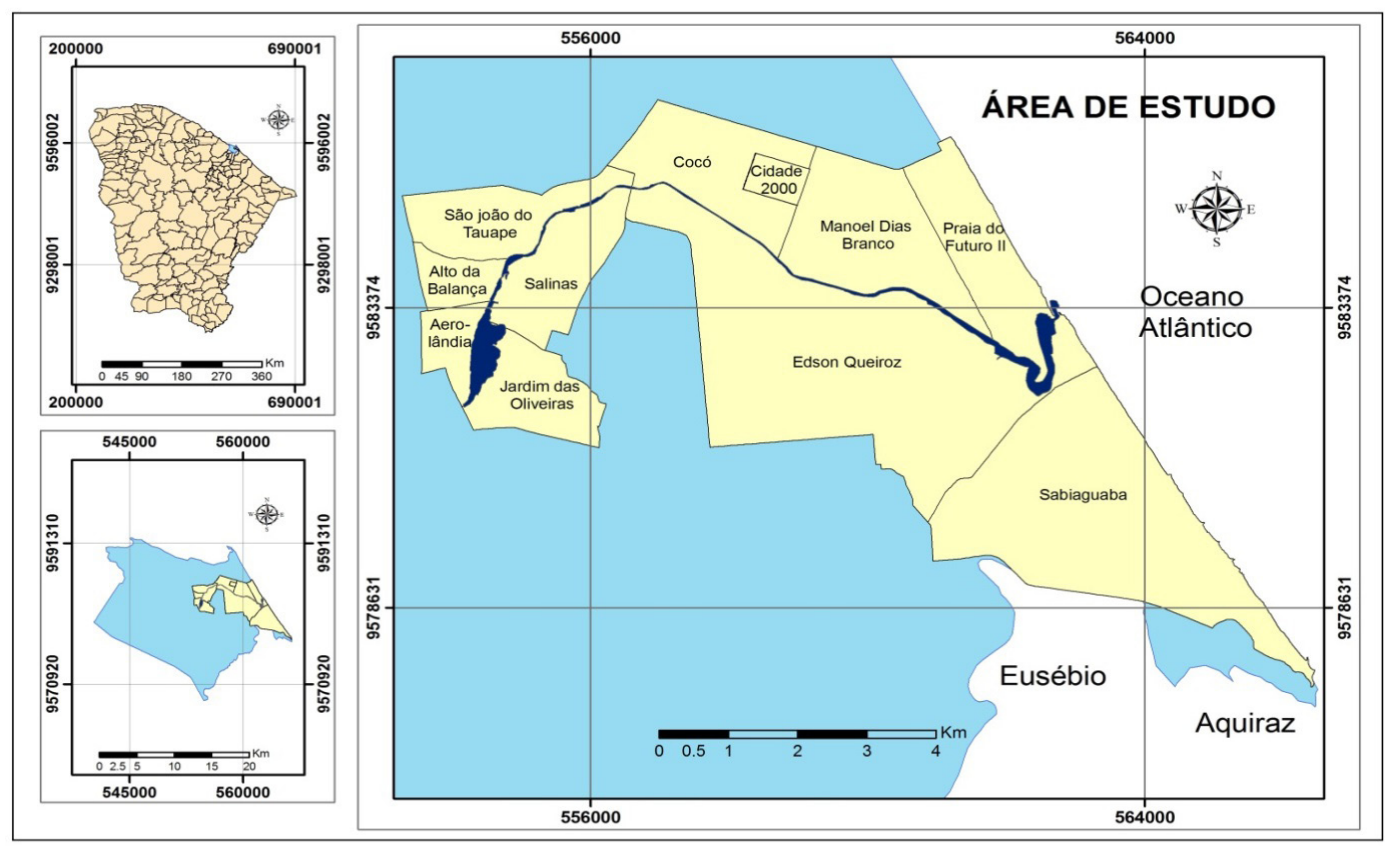

Fonte: elaboração dos autores.

\section{Pressupostos teóricos}

De acordo com Cunha (2005) o melhor método para identificação de mudanças fluviais provocadas pelas ações humanas é aquele que se apoia no monitoramento das modificações do canal, em locais-marco. Para aplicação desse método são necessários dados coletados durante algum tempo, o que requer observações anteriores às modificações, muitas vezes obtidas em fotos aéreas.

Com avanço tecnológico nas últimas décadas e o desenvolvimento de satélites artificiais, com a consequente aquisição de imagens da superfície terrestre através do sensoriamento remoto, o método anterior pode ser aplicado de forma mais eficiente, tendo em vista a quantidade e qualidades das imagens colhidas.

Segundo Florenzano (2002) sensoriamento remoto é o termo usado para descrever a tecnologia que permite obter imagens e outros tipos de dados, da superfície da Terra, através da captação e do registro da energia refletida ou emitida pela superfície. O termo sensoriamento é utilizado para se referir à obtenção dos dados, enquanto o remoto significa distante, ou seja, é a obtenção de dados sem o contato físico entre o sensor e a superfície terrestre.

As imagens de satélite nos fornecem uma visão sinóptica (de conjunto) e multitemporal (de dinâmica) de extensas áreas da superfície terrestre. Elas mostram os ambientes e as suas transformações, destacam os impactos causados por fenômenos naturais e antrópicos através do uso e da ocupação do espaço (FLORENZANO, 2002).

Geografia Ensino \& Pesquisa, v. 17, n.3, p. 153-174, set./dez. 2013.

Freire, E. V.; Gomes, D. D. M.; Sabadia, J. A. B., Duarte, C. R.; Souto, M. V. S. 
Além disso, foram desenvolvidos sistemas computacionais, conhecidos como Sistemas de Informações Geográficas (SIG's), com ferramentas que permitem operar sobre imagens de satélites na busca de levantamento de informações de interesse e assim garantir um ganho de conhecimento. Sendo possível através de imagens multitemporais a aquisição do quadro ambiental pretérito e atual de determinada área.

De acordo com Silva (2001) um SIG é um sistema que tem capacidade de operar sobre dados - que são apenas registros de ocorrência de fenômenos identificados - reestruturando-os para que se possa obter conhecimento sobre posições, extensões e relacionamentos taxonômicos, espaciais e temporais contidos em suas bases de dados. Além das possibilidades de atualização de seus dados, um SIG precisa dispor de mecanismos que permitam a transformação desses registros de ocorrência em ganho de conhecimento e facilite a verdadeira comunicação. Deve trazer aos dados, da forma mais direta e clara possível, o significado das transformações executadas e, assim, propiciando o partilhamento da informação entre os usuários.

Vários são os estudos que integram os dados do sensoriamento remoto às ferramentas operacionais dos Sistemas de Informações Geográficas. A partir dessa interação é possível realizar levantamentos, análise e relacionamentos em determinada situação ambiental e gerar consequentemente informações relevantes que poderão orientar tomadas de decisão sobre a realidade analisada.

Jacintho (2003) elaborou um quadro diagnóstico da Área de Proteção Ambiental (APA) do Capivari Monos na Região Metropolitana de São Paulo com informações produzidas através da aplicação de geoprocessamento e sensoriamento remoto. Imagens dos satélites LANDSAT - 5 e LANDSAT - 7 foram comparadas, com emprego de técnicas de detecção de mudanças (NDVI), para quantificação do desmatamento no período entre 1991 e 2000 . Os resultados foram quantificados por sub-bacias hidrográficas, compondo um quadro comparativo que se destina a subsidiar a gestão ambiental da APA.

Junior e Sousa (2007) realizaram uma análise multitemporal da cobertura vegetal no Parque Estadual de Bacanga, localizado em São Luís do Maranhão. Através da subtração de imagens LANDSAT-5 de 1984 e 2004 em ambiente SPRING, concluíram que ao longo dos vinte anos o parque apresentou-se conservado, com ampliação da cobertura vegetal não alterada e crescimento das áreas regeneradas.

Freires (2009) detectou mudanças na cobertura vegetal do município de Maracanaú-CE a partir de imagens Landsat-5 de 1991 e 2006 utilizando os SIG's SPRING e TERRAVIEW. Concluiu que para o período de 15 anos houve um incremento de aproximadamente $8 \%$ na área desmatada da cidade.

Gomes (2011) identificou e quantificou os níveis de degradação da cobertura vegetal na área da Bacia Hidrográfica do Rio Jaibaras/CE, entre os anos de 1985, 1992, 1996, 2007 e 2009, através do uso de técnicas de processamento digital de imagens foram elaborados os mapas temáticos dos níveis de degradação da cobertura vegetal da bacia hidrográfica.

Silva (2001) afirma que os estudos espaciais e temporais permitem estudar os ambientes em constante evolução, isto pode ser realizado se considerarmos os cenários do tipo prospectivo, pensando no futuro ou do tipo retrospectivo quando referente a situações passadas.

A análise temporal apresenta-se como uma excelente ferramenta para avaliação

Geografia Ensino \& Pesquisa, v. 17, n.3, p. $153-174$, set./dez. 2013

Análise da evolução urbana no entorno do estuário do Rio Cocó - Fortaleza/Ceará... das mudanças que ocorreram no entorno do estuário do Cocó nas últimas décadas. O reconhecimento das alterações que se processaram ao longo do tempo na paisagem local pode se tornar um recurso de suporte ao planejamento, gestão e fiscalização do Parque Ecológico do Cocó com vista a evitar novas intervenções, propor adequações de uso, orientar a recuperação de áreas degradadas, bem como, servir como indicador para quantificação de impactos ambientais a partir evolução urbana. 


\section{Materiais e métodos}

O desenvolvimento do trabalho foi realizado em duas etapas, conforme pode ser observado na Figura 2. Uma relacionada com a criação do banco de dados, no SPRING 5.0.6, outra com a criação do banco de dados no TERRAVIEW 3.3.0. No SPRING foram elaborados, a partir das imagens TM/Landsat-5, os mapas de uso e cobertura do solo para os anos de 1985, 1996 e 2007. No TERRAVIEW os mapas de uso e cobertura do solo foram submetidos à técnica de sobreposição que permitiu avaliar a evolução urbana na área de estudo para os períodos de 1985 1996, 1996-2007 e 1985-2007. A descrição dessas etapas é feita nos tópicos subsequentes.

O trabalho de campo subsidiou a interpretação visual das imagens e permitiu o levantamento de impactos da urbanização no estuário do Rio Cocó.

Figura 2 - Fluxograma da metodologia.

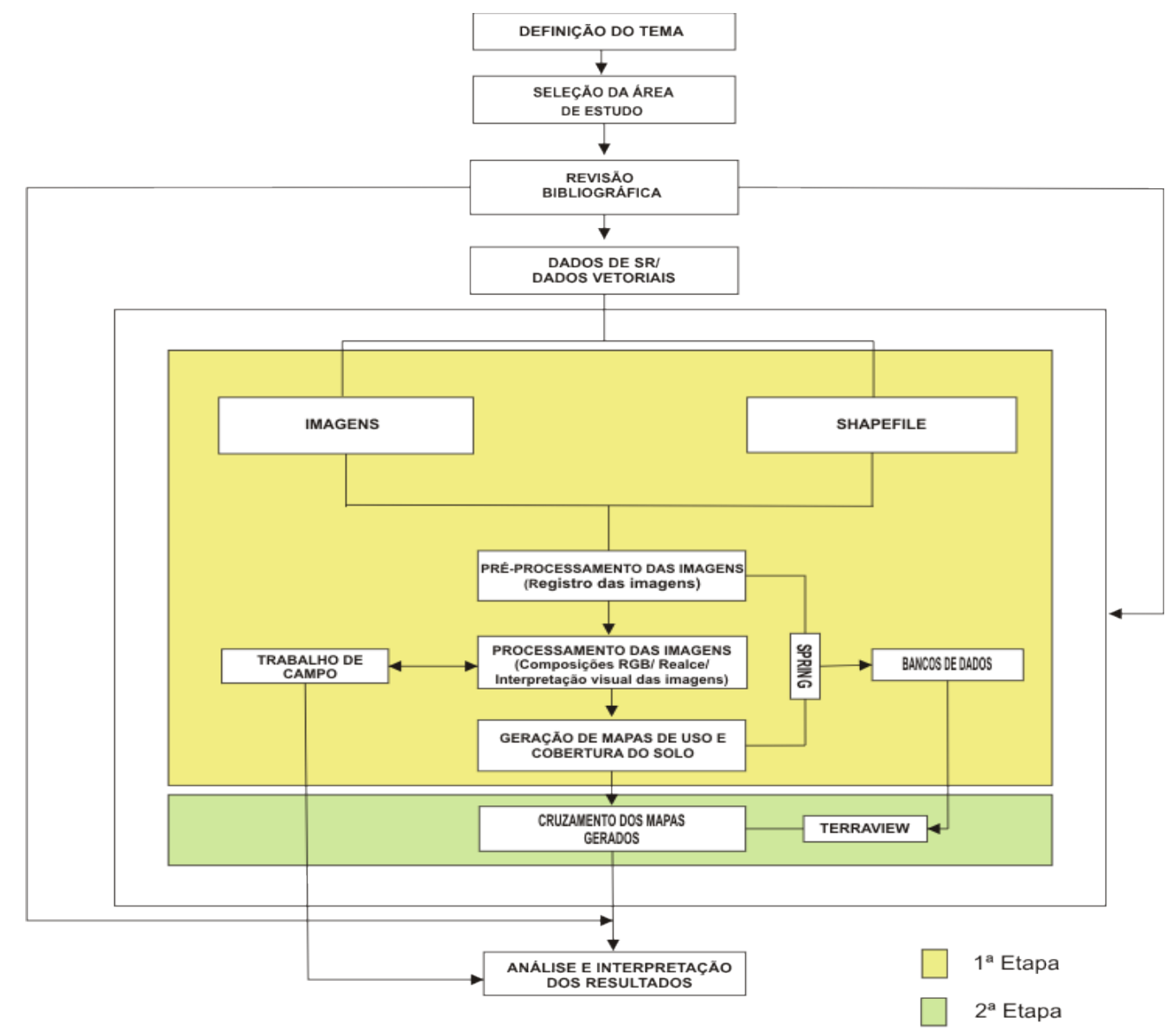

Fonte: elaboração dos autores.

\section{Materiais}

- Imagens orbitais TM/Landsat5 nas bandas 1, 2, 3, 4, 5 e 7 de 20/07/1985, 02/07/1996 e 15/06/2007, situam se na órbita 217, ponto 63 e foram de obtidas no catálogo de imagens do INPE-Brasil (2011).

- Imagem Geocover 2000, setor s-2400-2000 georreferenciada e ortorretificada (NASA, 2010).

- Dados vetoriais: Base vetorial dos Bairros e da drenagem de Fortaleza obtido na Secretaria de Infraestrutura de Fortaleza (SEINF);
Geografia Ensino \& Pesquisa, v. 17, n.3, p. 153-174, set./dez. 2013.

Freire, E. V.; Gomes, D. D. M. Sabadia, J. A. B., Duarte, C. R.; Souto, M. V. S. 
- A Imagem do Sensor MS do Satélite Quick Bird da Digital Globe, pixel de 2,4 m, de 2009 da bacia do Rio Cocó (SEMACE), e Fotografias aéreas da bacia do rio Cocó do ano de 1988 na escala de 1:7.500 (SEINF) utilizadas como suporte para interpretação visual das imagens TM/Landsat-5.

- Sistema de Processamento de Informações Georreferenciadas - SPRING 5.0.6 DPI/INPE, 2011).

- TerraView versão 3.3.0 (DPI/INPE, 2011).

\section{Métodos}

\section{Criação do Banco de Dados}

Para a criação do banco de dados foi utilizado o programa SPRING 5.0.6, cujo gerenciador utilizado foio MSAccess por possuir boa versatilidade no trabalho de consultas, seleções e relacionamentos entre dados.

Foi criado o banco de dados BD_RIO_COCÓ com as seguintes categorias: Imagens, Shapes, Geocover e Mapas.

Dentro da Categoria Mapas foram definidas 09 unidades de uso e cobertura do solo: Área Urbana; Rio; Vegetação Natural; Planície Hipersalina; Lagoas e alagadiços; Dunas; Faixa de Praia; lagoas Interdunares Intermitentes; Banco de Areia.

O passo seguinte foi à definição do projeto dentro do banco de dados BD_RIO_COCÓ,ou seja, a delimitação do projeto que envolve a área de estudo: o estuário do Rio Cocó.

Tal projeto recebeu o nome de Urbanização_Cocó, tendo como projeção o sistema UTM (Universal Transverso Mercator) com o Datum SAD 69. Para o retângulo envolvente foram utilizadas as seguintes coordenadas: $9.575 .044 \mathrm{~m}$ e $9.588 .317 \mathrm{~m} \mathrm{~N} ; 551.325 \mathrm{~m}$ e $568.070 \mathrm{~m}$ E.

Pré-processamento das imagens

O pré-processamento das imagens envolveu o registro das imagens TM/Landsat- 5 de 1985, 1996 e 2007. As cenas das três datas foram arquivadas em seis bandas espectrais (1, 2, 3, $4,5,7)$ em diferentes pastas conforme data de imageamento.

Antecedendo o registro as imagens foram submetidas ao módulo IMPIMA, para que as mesmas fossem convertidas para o formato SPG, que é o formato que o SPRING reconhece.

A partir do banco de dados BD_RIO_COCÓ, as imagens, TM/Landsat-5 de 1985, 1996 e 2007 foram registradas tendo como base de referência a imagem Landsat Geocover 2000.

$\mathrm{O}$ registro foi realizado imagem-imagem mediante o reconhecimento de 10 pontos de controle na imagem Landsat Geocover de 2000, com grau de polinômio 1 e reamostragem por vizinho mais próximo, em projeção cartográfica UTM e datum SAD 69, gerando um produto cujo Erro Médio Quadrático (RMS) foi de 0,18 pixel, que equivale a um pouco mais de 5 metros no terreno.

Geografia Ensino \& Pesquisa, v. 17, n.3, p. $153-174$, set./dez. 2013

Análise da evolução urbana no entorno do estuário do Rio Cocó - Fortaleza/Ceará...
Processamento das imagens

Composições em sistema de cores RGB - Visando o reconhecimento e interpretação dos alvos ou dos elementos que compõem a paisagem para a definição das unidades de uso e cobertura do solo da área de estudo, foram utilizadas diferentes composições coloridas no sistema de cores RGB para as bandas que compõem as imagens do satélite TM/Landsat-5 obtidas em 1985, 1996 e 2007.

Conforme sugerido por Florenzano (2008) foi utilizada a composição em RGB 453 para identificação da morfologia, lâmina d'água e rede de drenagem. Conforme a autora as melhores composições coloridas para o mapeamento de unidades geomorfológicas são aquelas obtidas com pelo menos duas imagens do infravermelho, como a composição admitida nessa pesquisa (4-infravermelho próximo; 5 -infravermelho médio; 3 -visivel). 
Seguindo ainda proposta de Florenzano (2008), para discriminação de feições culturais (urbano e rural), foram utilizadas as composições 432 e 473. Conforme salientado pela autora, para identificação de feições culturais é fundamental incluir duas bandas do visível (4 -infravermelho próximo; 3 - visível; 2 - visível) ou a banda 7 do infravermelho médio ( 4 -infravermelho próximo; 7 -infravermelho médio; 3 -visível).

Seguindo a metodologia proposta por Grigio (2003), foi utilizada a composição em RGB 542 para destacar as áreas de dunas e diferenciar as dunas fixas das dunas móveis, além de realçar a distribuição da cobertura vegetal.

Realce de imagem - Para facilitar a interpretação visual das diversas composições em RGB foram aplicadas técnicas de contraste as imagens TM/Landsat-5. Foram efetuados contrastes interativos, com manipulação do histograma, visando à melhoria da qualidade visual das imagens para a extração de informações específicas de interesse da pesquisa, já que existe a possibilidade de se obter uma imagem mais adequada para a interpretação e identificação dos atributos da paisagem, favorecendo, consequentemente, um resultado mais preciso.

Interpretação visual das imagens - Após o realce aplicado às imagens TM/Landsat-5 de 1985, 1996 e 2007, as mesmas foram vetorizadas manualmente, através da ferramenta edição vetorial, para se adquirir unidades de uso e cobertura do solo, necessárias para produção dos mapas temáticos.

Antes desse processo foram definidas 09 unidades de uso e cobertura do solo a partir dos levantamentos feitos em campo e de consultas aos mapas de uso do solo e de unidades fitoecológicas presente no site http:/ atlas.sth.cegov. br/. As unidades de uso e cobertura do solo foram Área Urbana; Rio; Vegetação Natural; Planície Hipersalina; Lagoas e alagadiços; Dunas; Faixa de Praia; lagoas Interdunares Intermitentes; Bancos de Areia. Para cobertura vegetal representada pela Vegetação Paludosa Marítima de Mangue, Vegetação de Dunas, Vegetação Psamófila e Vegetação de Tabuleiro foi definida apenas uma unidade denominada Vegetação Natural, pelo fato de a resolução espacial da imagem TM/Landsat-5 não permitir uma distinção significativa entre esses alvos.

A partir da vetorização foi originado o shapefile do uso e cobertura do solo nas diferentes datas, denominados de Shape_1985, Shape_1996 e Shape_2007.

Em seguida foi realizado um ajuste final nos shapes gerados das diferentes datas e um relacionamento dos polígonos criados na vetorização com as nove unidades de uso e cobertura do solo definidas na categoria Mapas.

Para que houvesse exatidão no relacionamento das unidades de uso e cobertura do solo aos polígonos gerados sobre as imagens TM/Landsat-5 de 1985, 1996 e 2007, foram consultados o material cartográfico de Ribeiro (2010), fotografias aéreas de 1988 e 2000 obtidas na SEINF, Mapas do diagnóstico Geoambiental de Fortaleza, o mapa digital de usos dos solos e o mapa fitoecológico da Secretaria de Recursos Hídricos do Estado do Ceará (disponível em:http:/ /atlas.srh.ce.gov.br/), Imagem Quick Bird de 2009 cedida pela Semace, o programa Google Earth, bem como, o reconhecimento terrestre obtido nas atividades de campo.

De acordo com Florenzano (2008), “O conhecimento prévio da área geográfica e aquele sobre o tema de estudo (relevo, vegetação, área urbana etc.) facilitam o processo de interpretação e aumentam o potencial de leitura de uma imagem".

Logo em seguida foi realizada a delimitação da área de estudo a partir da criação de um polígono base, que teve como referência os limites dos bairros adjacentes ao estuário do Rio Cocó, visualizados através do shape dos bairros de Fortaleza obtidos na SEINF. Os bairros inseridos em tal delimitação foram: Jardim das Oliveiras, Salinas, Edson Queiroz, Sabiaguaba (na margem direita do rio) e Aerolândia, Alto da Balança, São João do Tauape, Cocó, Cidade 2000, Manoel Dias Branco, Praia do Futuro II (na margem esquerda do rio).

A partir da ferramenta Recortar Plano de Informação os shapes dos anos de 1985, 1996 e 2007 foram recortados através do polígono base de delimitação da área de interesse.

Como resultado da interpretação visual e do recorte dos shapefiles foram gerados os mapas de uso e cobertura do solo da área de estudo para os anos de 1985, 1996 e 2007.

Geografia Ensino \& Pesquisa, v. 17, n.3, p. 153-174, set./dez. 2013.

Freire, E. V.; Gomes, D. D. M.; Sabadia, J. A. B., Duarte, C. R.; Souto, M. V. S. 
Cruzamento dos mapas gerados dos anos de 1985, 1996 e 2007

O cruzamento dos mapas objetivou a detecção do crescimento da área urbana no decorrer do período analisado. Para tanto foi aplicado o método de diferença presente na ferramenta Operação Geográfica do software TERRA VIEW 3.3.0.

Através do método de diferença os mapas ou temas de interesse são cruzados e o resultado é um terceiro mapa apenas com as diferenças de área entre aqueles temas. Isso ocorre porque esse método reconhece as áreas coincidentes dos polígonos gerados em cada mapa, aparando-as, e expondo as diferenças.

Esse método foi aplicado à unidade de uso e cobertura do solo Área Urbana dos mapas de 1985 e 1996, 1996 e 2007, e também, 1985 e 2007. Como resultado dessa operação, foram gerados três mapas: um contendo a evolução urbana ocorrida entre 1985 e 1996, outro com a evolução urbana do período entre 1996 e 2007 e um terceiro com a evolução urbana que se processou no período compreendido entre 1985 e 2007.

\section{Trabalho de campo}

Com o objetivo de realizar com exatidão a interpretação visual das Imagens TM/Landsat- 5 de 1985, 1996 e 2007 com vista a gerar os mapas de uso e cobertura do solo das respectivas datas, foram realizadas várias visitas a campo para o reconhecimento visual da área de estudo. Além disso, foram feitos levantamentos de dados históricos em instituições públicas (SEINF, Secretaria das Cidades, Semace, Biblioteca Pública), trabalhos acadêmicos e sites oficiais visando identificar as edificações que surgiram no período e comprovar a evolução urbana local. Os dados históricos permitiram ainda identificar medidas governamentais de preservação da área como a criação do Parque Ecológico do Cocó que culminou na recuperação do mangue nas antigas salinas.

Nos dias 11 de abril de 2010 e 1 de março de 2011 foram realizadas as primeiras visitas na área estudo. Essas visitas antecederam o processamento das imagens e serviram para identificar, na medida do possível, os elementos ou alvos que compõem a paisagem a fim de que fossem definidas as unidades de uso e cobertura do solo.

Durante o processo de geração dos mapas foi realizada uma visita à área de estudo no dia 10 de julho de 2011. Essa atividade consistiu num processo de constatação do que estava sendo visualizado no momento de interpretação visual das imagens, ou seja, se os polígonos apontados como unidades de uso e cobertura correspondiam à realidade encontrada no campo.

No dia 30 de dezembro foi realizada outra visita a campo no intuito de eliminar quaisquer dúvidas e consequentemente realizar o fechamento dos mapas de uso e cobertura do solo.

A partir da verificação de campo e do levantamento de dados históricos foram identificados e corrigidos nos mapas os alvos incompatíveis com a realidade da área de estudo.

Além disso, em todas as atividades de campo, foram identificados e registrados, através de fotos, os impactos ambientais negativos ao longo do estuário. Durante os trabalhos de campo foram realizadas conversas informais com os moradores da área visitada no intuito de obter informações sobre o quadro pretérito e atual da intervenção humana sobre estuário.

\section{Resultados e discussão}

Geografia Ensino \& Pesquisa, v. 17, n.3, p. $153-174$, set./dez. 2013

Análise da evolução urbana no entorno do estuário do Rio Cocó - Fortaleza/Ceará..
Evolução de uso da cobertura do solo da área de entorno do estuário do Rio Cocó entre os anos de 1985, 1996 e 2007

A partir interpretação visual das imagens foram gerados mapas de uso e cobertura do solo dos anos de 1985, 1996 e 2007. Para cada mapa foram definidas 09 unidade de uso cobertura do solo: Área Urbana; Rio; Vegetação Natural; Planície Hipersalina; Lagoas e alagadiços; Dunas; Faixa de Praia; lagoas Interdunares Intermitentes e Banco de Areia (Figuras 3, 4 e 5). 
A área de cada uma dessas unidades foi quantificada, o que permitiu avaliar a evolução urbana ao longo do período analisado.

Figura 3 - Mapa de uso e cobertura do solo no ano de 1985.

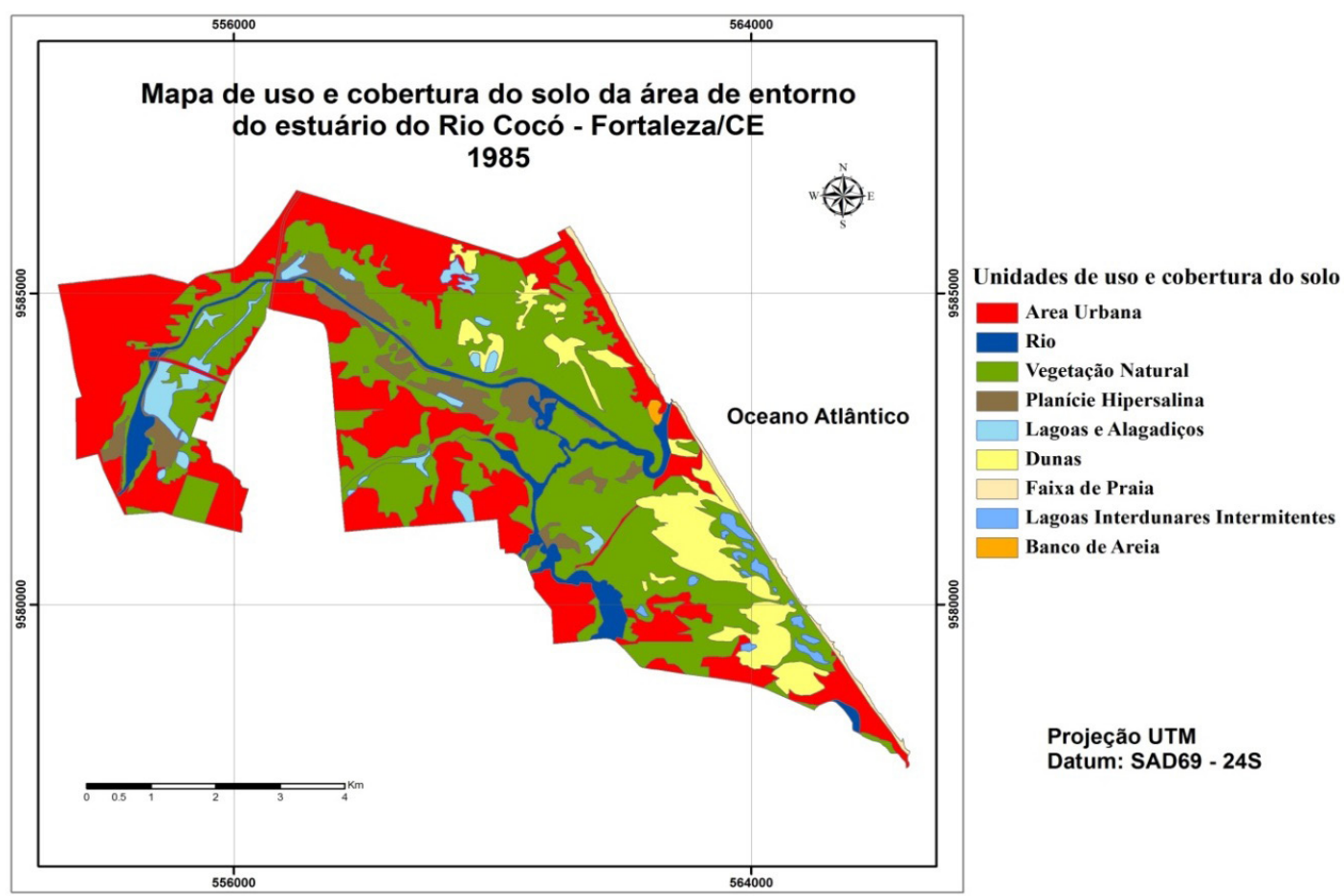

Fonte: elaboração dos autores.

Figura 4 - Mapa de uso e cobertura do solo no ano de 1996.

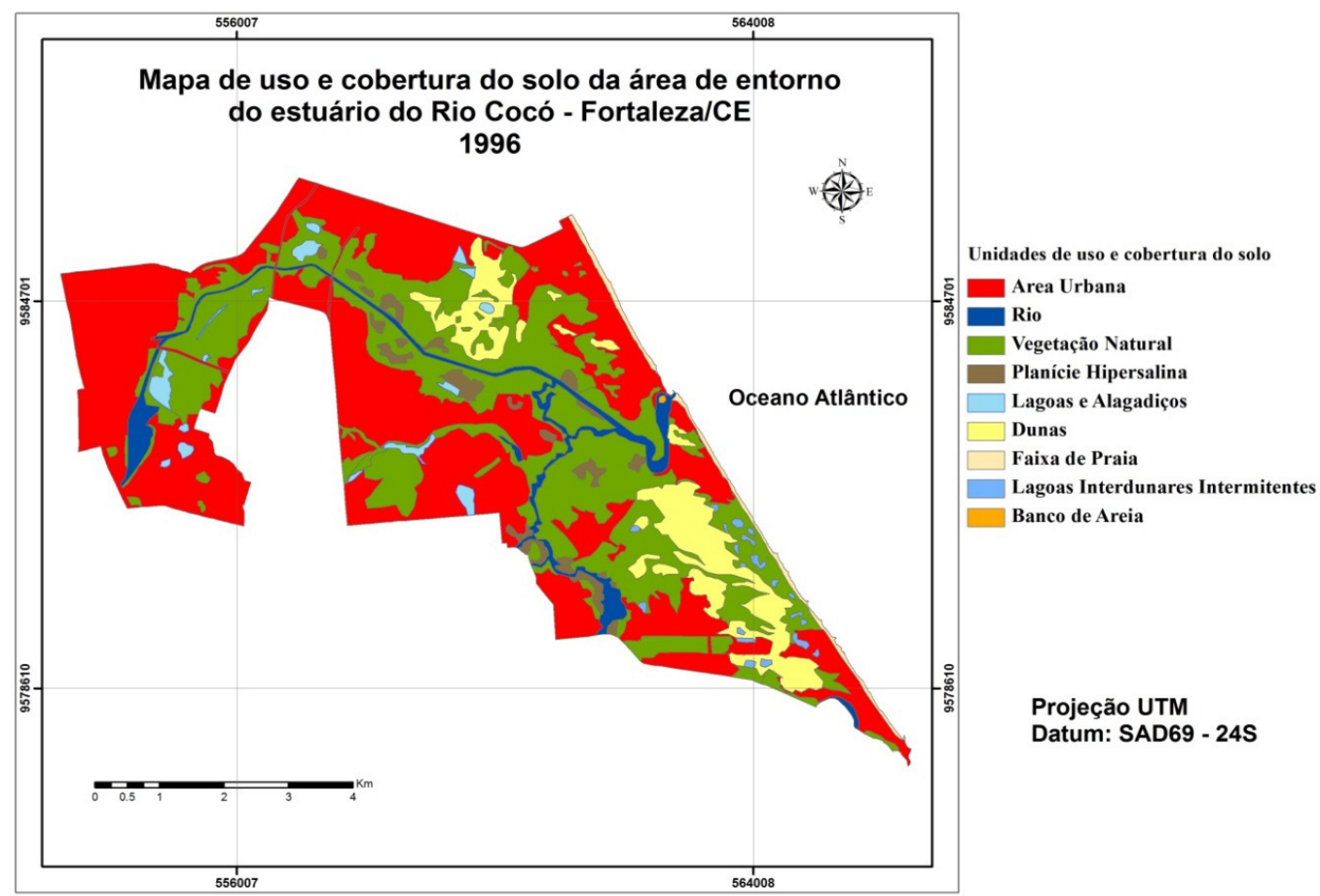

Fonte: elaboração dos autores.

Geografia Ensino \& Pesquisa, v. 17, n.3, p. 153-174, set./dez. 2013.

Freire, E. V.; Gomes, D. D. M.; Sabadia, J. A. B., Duarte, C. R.; Souto, M. V. S. 
Figura 5 - Mapa de uso e cobertura do solo no ano de 2007.

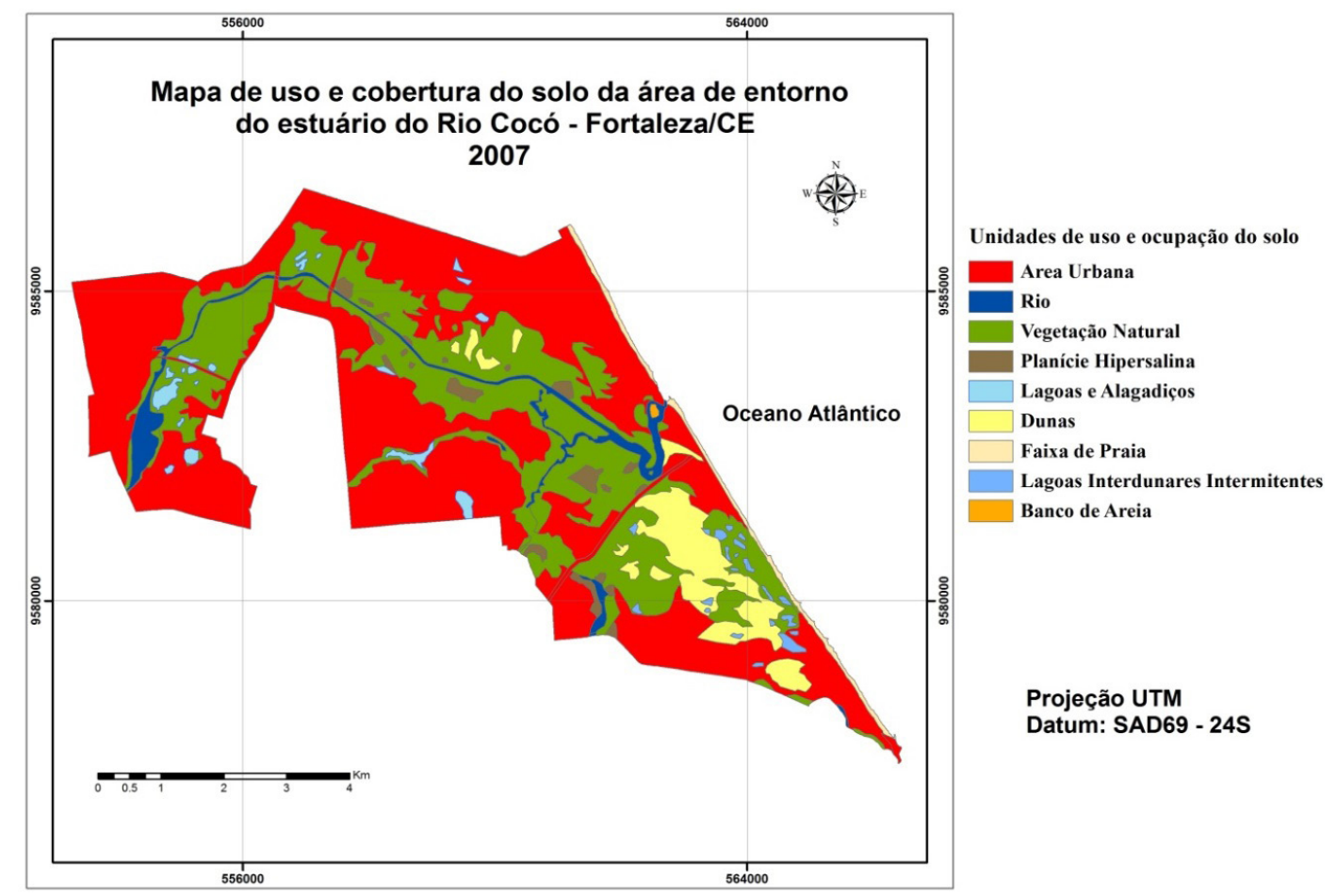

Fonte: elaboração dos autores.

As modificações que ocorreram no entorno do estuário do Rio Cocó podem ser constatadas a partir das mudanças nas áreas das unidades de uso e cobertura do solo nos anos de 1985, 1996 e 2007, que se encontram expressas na Tabela 1 e comparados no Figura 6.

A Área Urbana foi a unidade que apresentou a mudança mais expressiva entre 1985 e 2007. Entre 1985 e 1996 houve um crescimento de 12,95\% (5,85 $\left.\mathrm{Km}^{2}\right)$ em sua área, enquanto no período entre 1996 e 2007 o seu avanço continuou e apresentou um incremento de $8.49 \%$ $\left(3,84 \mathrm{Km}^{2}\right)$. Durante o período analisado a malha urbana cresceu 9,69 $\mathrm{Km}^{2}$. A ampliação da Área Urbana se deu a partir de seu avanço sobre as demais unidades de uso e cobertura do solo, como Vegetação Natural, Rio, Planície Hipersalina, Lagoas e Alagadiços, Dunas.

Tabela 1 - Comparação das unidades de uso e cobertura do solo para os anos de 1985, 1996 e 2007.

Geografia Ensino \& Pesquisa, v. 17, n.3, p. $153-174$, set./dez. 2013

Análise da evolução urbana no entorno do estuário do Rio Cocó - Fortaleza/Ceará..

\begin{tabular}{l|cc|c|c|c|c}
\hline \multirow{2}{*}{$\begin{array}{l}\text { Unidades de uso e } \\
\text { cobertura do solo }\end{array}$} & \multicolumn{6}{c}{$\mathbf{c}$ ANO } \\
\cline { 2 - 7 } & $\mathbf{K m}^{\mathbf{2}}$ & $\mathbf{1 9 8 5}$ & $\mathbf{K m}^{\mathbf{2}}$ & $\%$ & $\mathbf{K m}^{\mathbf{2}}$ & $\%$ \\
\hline Área Urbana & 15,44 & $\mathbf{3 4 , 1 8}$ & 21,29 & $\mathbf{4 7 , 1 3}$ & 25,13 & $\mathbf{5 5 , 6 2}$ \\
\hline Rio & 2,34 & $\mathbf{5 , 1 7}$ & 1,93 & $\mathbf{4 , 2 6}$ & 1,56 & $\mathbf{3 , 4 5}$ \\
\hline Vegetação Natural & 19,21 & $\mathbf{4 2 , 7}$ & 15,48 & $\mathbf{3 4 , 2 6}$ & 13,46 & $\mathbf{2 9 , 7 9}$ \\
\hline Planície Hipersalina & 2,34 & $\mathbf{5 , 1 7}$ & 1,10 & $\mathbf{2 , 4 3}$ & 0,77 & $\mathbf{1 , 7 0}$ \\
\hline Lagoas e Alagadiços & 1,30 & $\mathbf{2 , 8 7}$ & 0,70 & $\mathbf{1 , 5 4}$ & 0,54 & $\mathbf{1 , 1 9}$ \\
\hline Dunas & 3,64 & $\mathbf{8 , 0 5}$ & 3,94 & $\mathbf{8 , 7 1}$ & 2,86 & $\mathbf{6 , 3 2}$ \\
\hline Faixa de Praia & 0,50 & $\mathbf{1 , 1 0}$ & 0,50 & $\mathbf{1 , 1 0}$ & 0,55 & $\mathbf{1 , 2 1}$ \\
\hline Lagoas Interdunares & 0,37 & $\mathbf{0 , 8 1}$ & 0,25 & $\mathbf{0 , 5 5}$ & 0,31 & $\mathbf{0 , 6 8}$ \\
Intermitentes & 0,06 & $\mathbf{0 , 1 3}$ & 0,01 & $\mathbf{0 , 0 2}$ & 0,02 & $\mathbf{0 , 0 4}$ \\
\hline Banco de Areia & 45,20 & $\mathbf{1 0 0 , 0 0}$ & 45,20 & $\mathbf{1 0 0 , 0 0}$ & 45,20 & $\mathbf{1 0 0 , 0 0}$ \\
\hline TOTAL & & & & & & $\mathbf{2 0 0 7}$
\end{tabular}

Fonte: elaboração dos autores. 
Figura 6 - Evolução das unidades de uso e cobertura do solo nos anos de 1985, 1996 e 2007.

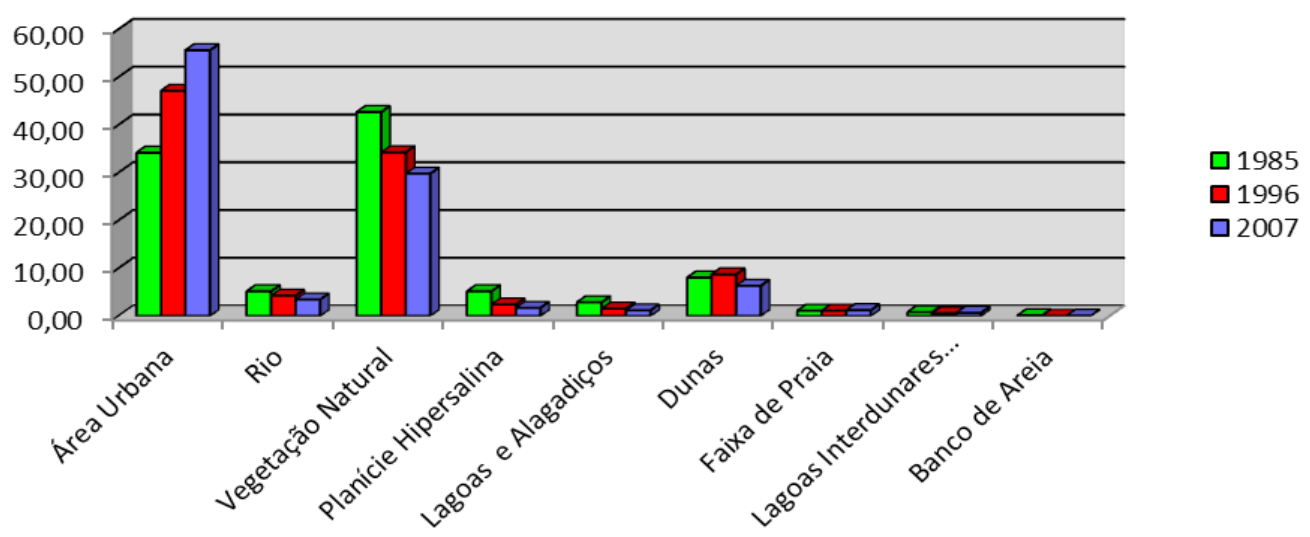

Fonte: elaboração dos autores.

Como pôde ser observado, entre as 09 unidades de uso e cobertura do solo mapeadas entre 1985 e 2007 a Área Urbana foi a única que apresentou crescimento. O incremento verificado na área urbana se deu à custa da redução nas áreas das demais unidades. No Figura 7 pode ser observado o crescimento da Área Urbana em relação às outras unidades no decorrer do período analisado.

Figura 7 - Comparação entre a evolução da área urbana e das demais.

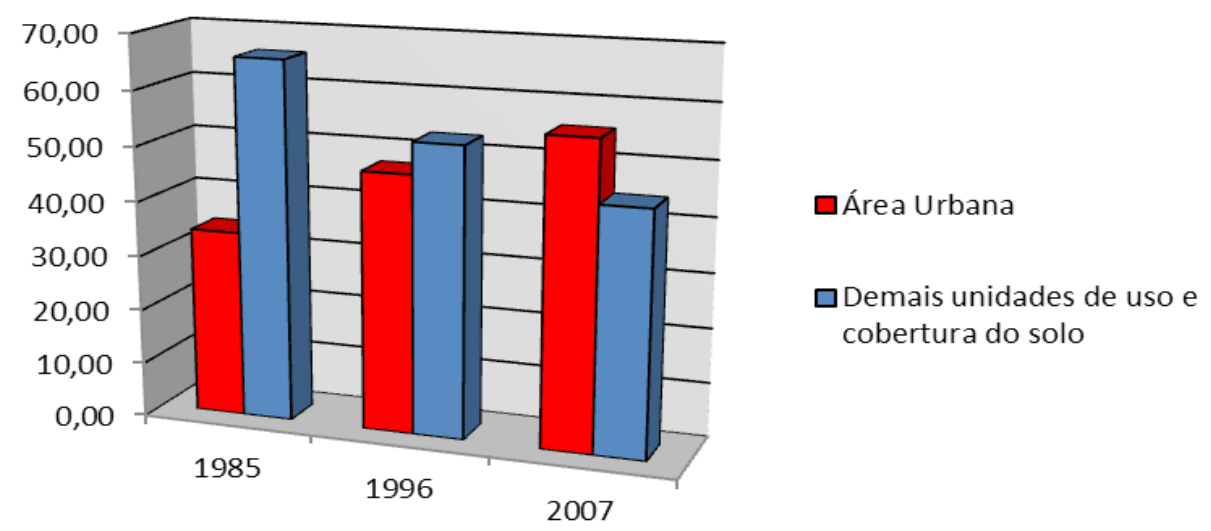

Fonte: elaboração dos autores.

Essa evolução esteve associada à construção de importantes avenidas, como a Sebastião de Abreu e a Governador Raul Barbosa (Figura 8), ao aumento de prédios residenciais e comerciais no entorno do estuário como resultado da especulação imobiliária, à construção de conjuntos habitacionais, e também a partir das ocupações irregulares na planície de inundação do Rio Cocó e nas dunas dos bairros Sabiaguaba, Manoel Dias Branco e Praia do Futuro.

Para a construção das Avenidas citadas anteriormente houve supressão da vegetação do mangue e forte acréscimo de materiais exógenos para um aterramento que oferecesse sustentação as obras. A Avenida Governador Raul Barbosa, segundo o Engenheiro Assis Bezerra, da Secretaria de Infra-Estrutura de Fortaleza (SEINF), foi construída entre 1992 e 1993 com uma extensão de aproximadamente três quilômetros, com três sentidos Norte-Sul e três Sul-Norte. Para edificação dessa avenida foi utilizada no pavimento pedra tosca, assentada sobre piçarra e areia de duna, e posteriormente revestida por asfalto. Essa Avenida se estende paralelamente a margem esquerda do estuário do Rio Cocó, nos bairros Aerolândia, Alto da Balança e São João do Tauape.

A construção dessas avenidas significou não só uma modificação imediata da paisagem, como também, implicou ao longo do tempo numa alteração no padrão de drenagem da planície fluviomarinha e na dinâmica hídrica e sedimentológica do estuário.

Geografia Ensino \& Pesquisa, v. 17, n.3, p. 153-174, set./dez. 2013.

Freire, E. V.; Gomes, D. D. M.; Sabadia, J. A. B., Duarte, C. R.; Souto, M. V. S. 
Figura 8 - Avenidas Sebastião de Abreu (1992) e Governador Raul Barbosa (1992 e 1993).
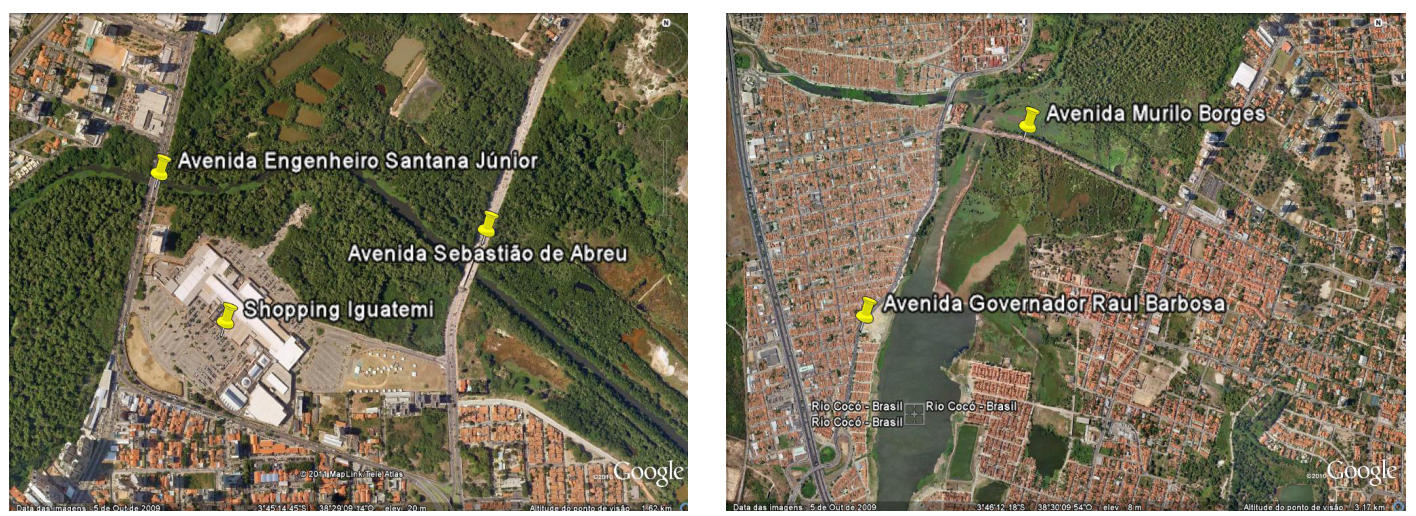

Fonte: programa Google Earth.

Conforme Silva (2003), as avenidas que foram edificadas transversalmente ao Rio Cocó, passaram a funcionar como uma barragem ao dificultar a passagem livre para oceano das águas drenadas da bacia hidrográfica, alterando a energia da corrente, que entre outras consequências, favorece uma deposição anormal de sedimentos nas porções anteriores às obras, sobretudo, na região montante do estuário, antes da Avenida Murilo Borges, onde ocorre o soterramento dos pneumatóforos do mangue e ocasiona a morte das árvores por asfixia. Além disso, essa avenida funciona como dique impedindo a entrada de águas marinhas na parte montante do estuário, essencial para o desenvolvimento do mangue.

No decorrer do período analisado surgiram vários conjuntos habitacionais na área de estudo, como podem ser observados na Figura 9.

Figura 9 - Conjuntos habitacionais construídos no entorno do estuário do Rio Cocó.

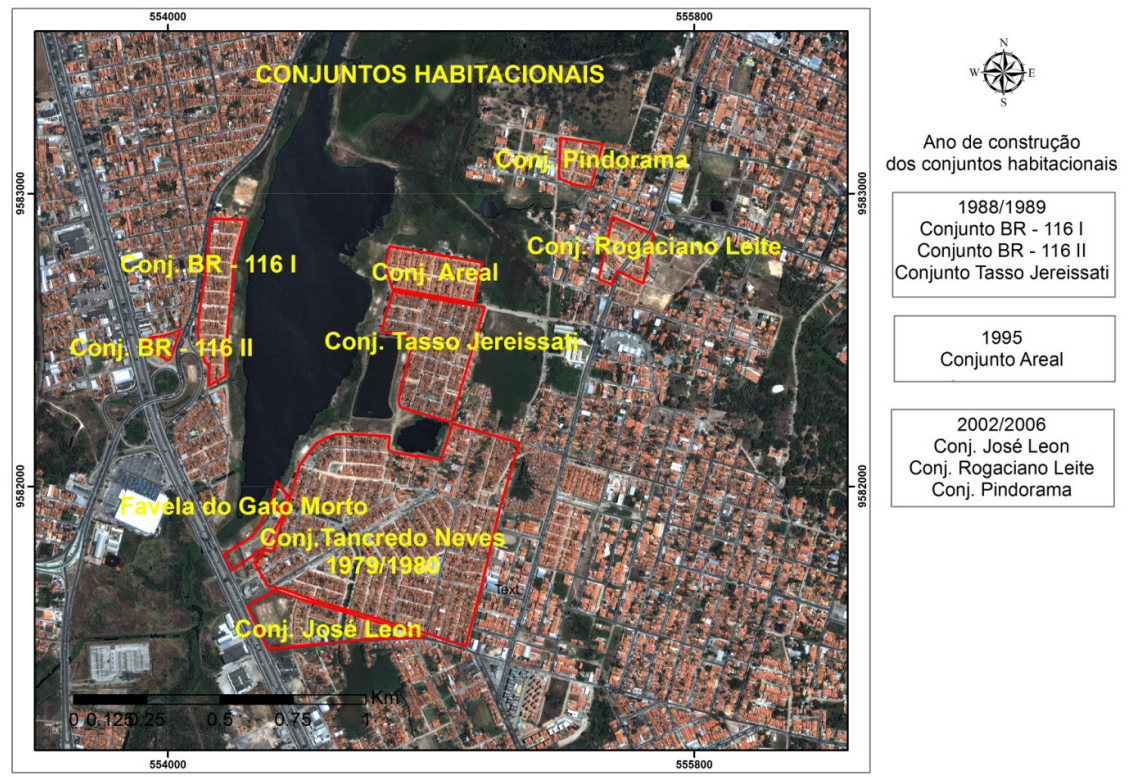

Fonte: programa Google Earth.

Geografia Ensino \& Pesquisa, v. 17, n.3, p. $153-174$, set./dez. 2013

Análise da evolução urbana no entorno do estuário do Rio Cocó - Fortaleza/Ceará...

164 ISSN 2236-4994
Entre 1988 e 1989 foram construídos os conjuntos habitacionais BR-116 I, BR-116 II, próximo à margem esquerda do Rio Cocó, e Conjunto Tasso Jereissati próximo a margem direita do Rio. Em 1995 foi construído, próximo a margem direita do Rio Cocó, o Conjunto Areal, assim denominado por ter sido necessário forte aterramento da área com areia de duna para eliminar os alagadiços e evitar inundações no período chuvoso. 
No período entre 2002 e 2006 o Governo do Estado do Ceará, através de recursos do Banco Interamericano de Desenvolvimento - BID, realizou o reassentamento dos moradores da Favela do Gato Morto (Figura 10), localizada às margens do Rio Cocó, próxima ao Conjunto Tancredo Neves e a BR-116. Para a transferência da população foram construídos os conjuntos José Leon, que abrigou 198 famílias, Rogaciano Leite, para 324 famílias e Pindorama, que comportou 215 famílias.

Figura 10 - Favela do Gato Morto durante estação chuvosa em Fortaleza, 2001.

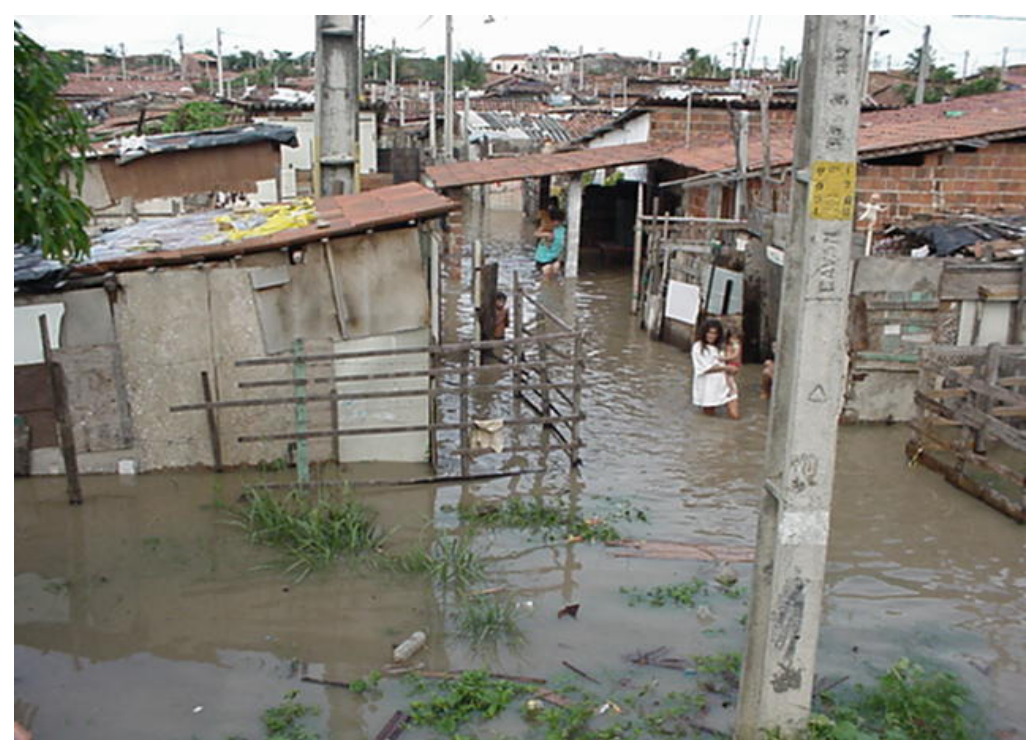

Fonte: Coordenadoria de Habitação, Secretaria das Cidades.

A área anteriormente ocupada pela Favela do Gato Morto foi urbanizada com o Pólo de Lazer Tancredo Neves, comportando quadras esportivas, campo de futebol, calçadão, ancoradouro e playgrounds. De acordo com José Wilson, engenheiro civil da Coordenadoria de Habitação da Secretaria das Cidades do Estado do Ceará, mesmo tal ação tendo recebido críticas por parte de ambientalistas, por se tratar de área de APP, essa medida foi imprescindível para evitar que o espaço fosse novamente ocupado por habitações insalubres.

Em 1997 foi Inaugurado no Bairro Edson Queiroz, ao lado da Unifor (Universidade de Fortaleza), a sede do Fórum Clóvis Beviláqua. Conforme o site do Tribunal de Justiça do Ceará (2012), "o prédio tem 75 mil metros quadrados de área construída e extensão horizontal de 330 metros, o que lhe confere o status de maior edifício público da América Latina". Essa obra juntamente com a oferta dos serviços prestados contribuiu para ampliação da especulação imobiliária e para intensificação do fluxo de pessoas na região.

Entre 1996 e 2007 destacam-se duas obras de ampliação realizadas no Shopping Center Iguatemi, localizado próximo à margem direita do Rio Cocó no bairro Guararapes: uma em 1999, para receber o Hipermercado Extra e mais duas áreas de estacionamento, e outra em 2001, para construção de um edifício garagem que acrescentou mais treze mil metros quadrados de área construída.

Em 2010 foi efetivada a mais recente expansão do Shopping, com a construção do Edifício Iguatemi Empresarial, que se deu em meio a amplo debate e protestos acerca de possíveis danos ao ecossistema e à legalidade para que a obra fosse implementada.

Conforme o site da Iguatemi Empresa de Shopping Center S.A (2011), o Shopping Center Iguatemi apresenta uma área total de mais de $120.000 \mathrm{~m}^{2} \mathrm{em}$ um terreno de 24 hectares. A área particular do Shopping sugere que novas expansões poderão ocorrer nos próximos anos caso aumente a demanda pelos seus serviços e haja por parte do poder público novamente o consentimento através de licença ambiental para execução da obra.
Geografia Ensino \& Pesquisa, v. 17, n.3, p. 153-174, set./dez. 2013.

Freire, E. V.; Gomes, D. D. M.; Sabadia, J. A. B., Duarte, C. R.; Souto, M. V. S.

ISSN 2236-4994 | 165 
A partir de 2006, o carnaval fora de época em Fortaleza (Fortal), que ocorria na Avenida Beira Mar no mês de julho, foi transferido para uma arena, denominada Cidade Fortal, no bairro Manoel Dias Branco, próximo ao estuário do Rio Cocó. De acordo com o site oficial do Fortal (2012), a Cidade Fortal apresenta mais de 200 mil metros quadrados e está preparada para receber mais de 80 mil pessoas por dia. Esse evento além de ter contribuído para supressão da cobertura vegetal, estimula a especulação imobiliária e consequentemente amplia os impactos negativos no local.

As intervenções humanas podem ser verificadas não só no entorno da planície fluviomarinha, como também às margens do Rio Cocó. São encontradas varias ocupações irregulares ao longo do seu trajeto, como podem ser observadas na Figura 11.

Essas ocupações são responsáveis pela retirada da mata ciliar, que desempenha importante função para o equilíbrio do rio ao estabilizar suas margens contra o efeito da corrente.

Uma vez eliminada essa vegetação, as margens do rio ficam expostas e são constantemente erodidas pela dinâmica fluvial, promovendo assim o assoreamento que reflete uma alteração no padrão sedimentológico, tendo em vista a contaminação por sedimentos que normalmente não seriam transportados.

Figura 11 - Ocupações à margem do Rio Cocó no bairro Manoel Dias Branco (Julho de 2011).

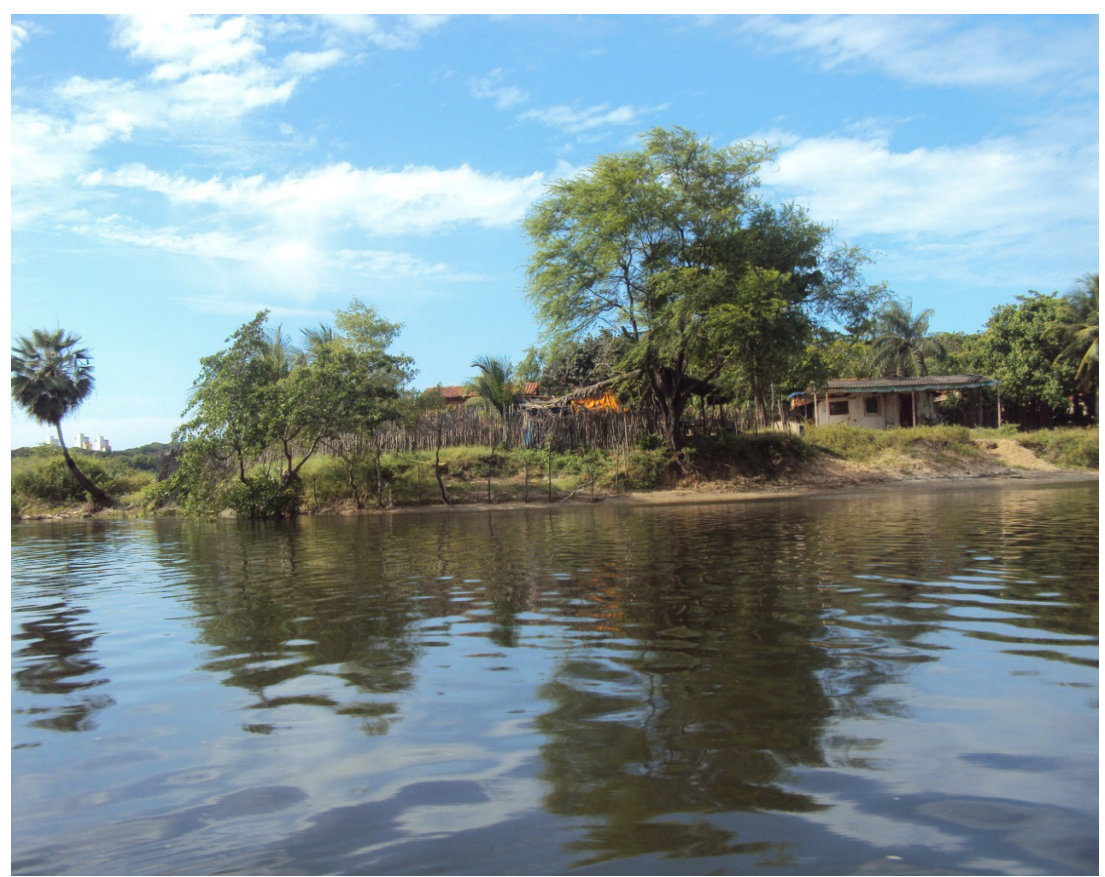

Fonte: elaboração dos autores.

Geografia Ensino \& Pesquisa, v. 17, n.3, p. $153-174$, set./dez. 2013

Análise da evolução urbana no entorno do estuário do Rio Cocó - Fortaleza/Ceará..
$\mathrm{Na}$ foz do Rio Cocó as ações antrópicas imperam em toda paisagem. No ano de 2002 a Prefeitura Municipal de Fortaleza iniciou as obras da Ponte de Sabiaguaba (Figura 12) visando ligar a Praia do Futuro à Praia de Sabiaguaba, separadas pela foz do Rio Cocó. A construção da ponte de Sabiaguaba prosseguiu até agosto de 2004, quando teve suas obras paralisadas. Em julho de 2009 o Departamento Nacional de Infraestrutura de Transportes assumiu a obra e finalmente pôde ser inaugurada em junho de 2010. Assim como as avenidas Murilo Borges, Engenheiro Santana Júnior e Sebastião de Abreu, sua edificação se deu a partir de desmatamento do mangue, seguido por aterramento e compactação do solo para suportar tal obra.

As margens da foz encontram-se ocupadas por barracas e bares que descaracterizam a paisagem e são responsáveis por despejos de esgotos, assoreamento do rio, deposição de entulho e contribui para aumentar o fluxo de pessoas que implica em mais alterações no local (Figura 13). 
Figura 12 - Ponte da Sabiaguaba (julho de 2011).

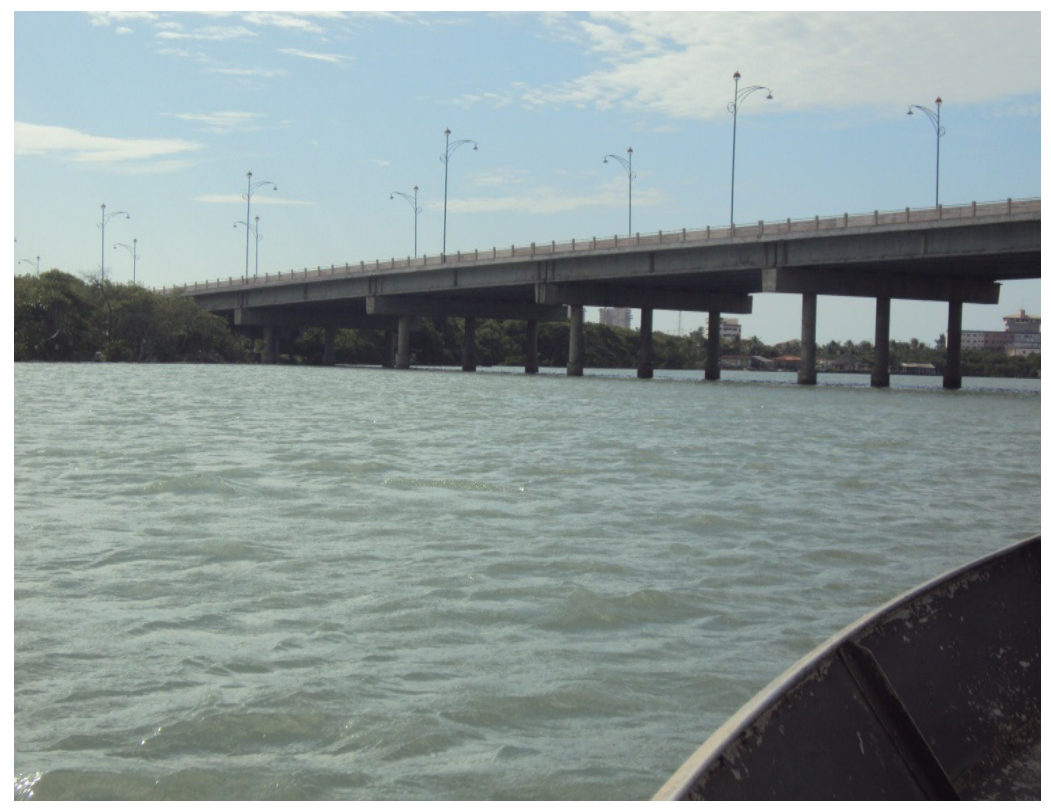

Fonte: elaboração dos autores.

Figura 13 - Barracas na margem direita da foz do Rio Cocó no Bairro Sabiaguaba (julho de 2011).

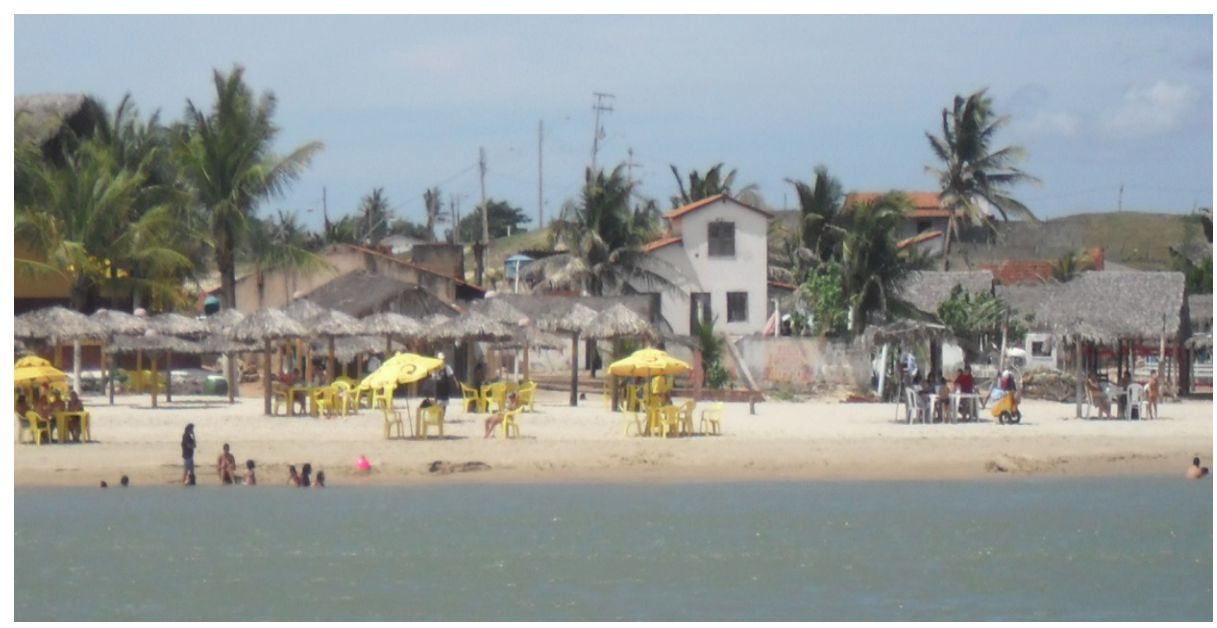

Fonte: elaboração dos autores.

Evolução Urbana no entorno do estuário do Rio Cocó ocorrida nos períodos de 1985/1996, 1996/ 2007 e 1985/2007.

A identificação da evolução urbana que se processou na área de estudo no decorrer do período analisado se deu a partir do cruzamento dos mapas de uso e cobertura do solo de 1985, 1996 e 2007 através da função diferença do programa TERRA VIEW.

As Figuras 14, 15 e 16 são resultados do cruzamento da Área Urbana dos mapas de uso e cobertura do solo de 1985 e 2007 (22 anos), 1985 e 1996 (11 anos) e 1996 e 2007 (11 anos). Os mapas representam as diferenças ou o incremento urbano verificado em cada período.

Geografia Ensino \& Pesquisa, v. 17, n.3, p. 153-174, set./dez. 2013.

Freire, E. V.; Gomes, D. D. M.; Sabadia, J. A. B., Duarte, C. R.; Souto, M. V. S. 
Figura 14 - Mapa contendo acréscimo de área urbana no período entre 1985 e 1996.

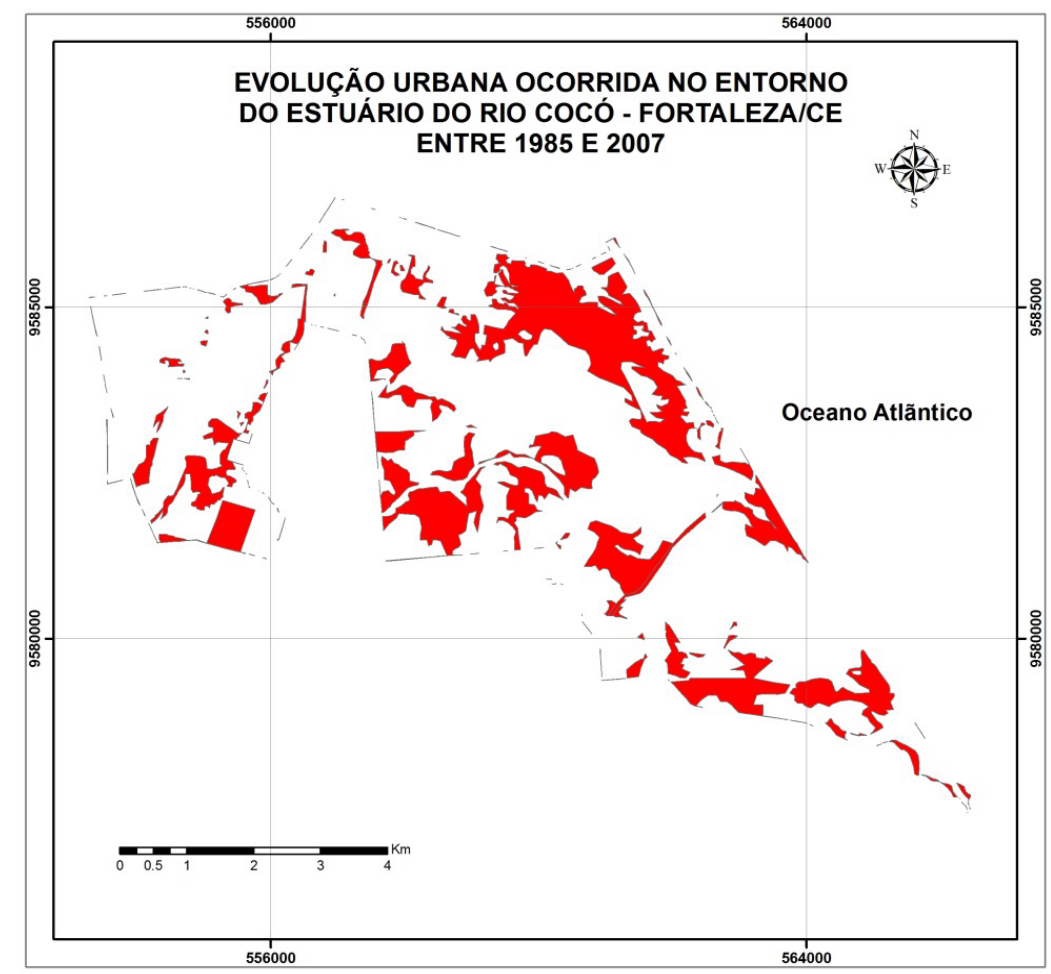

Legenda

Área Urbana

Projeção UTM

Datum: SAD69 - 24S

Fonte: elaboração dos autores.

Figura 15 - Mapa contendo acréscimo de área urbana no período entre 1985 e 1996.

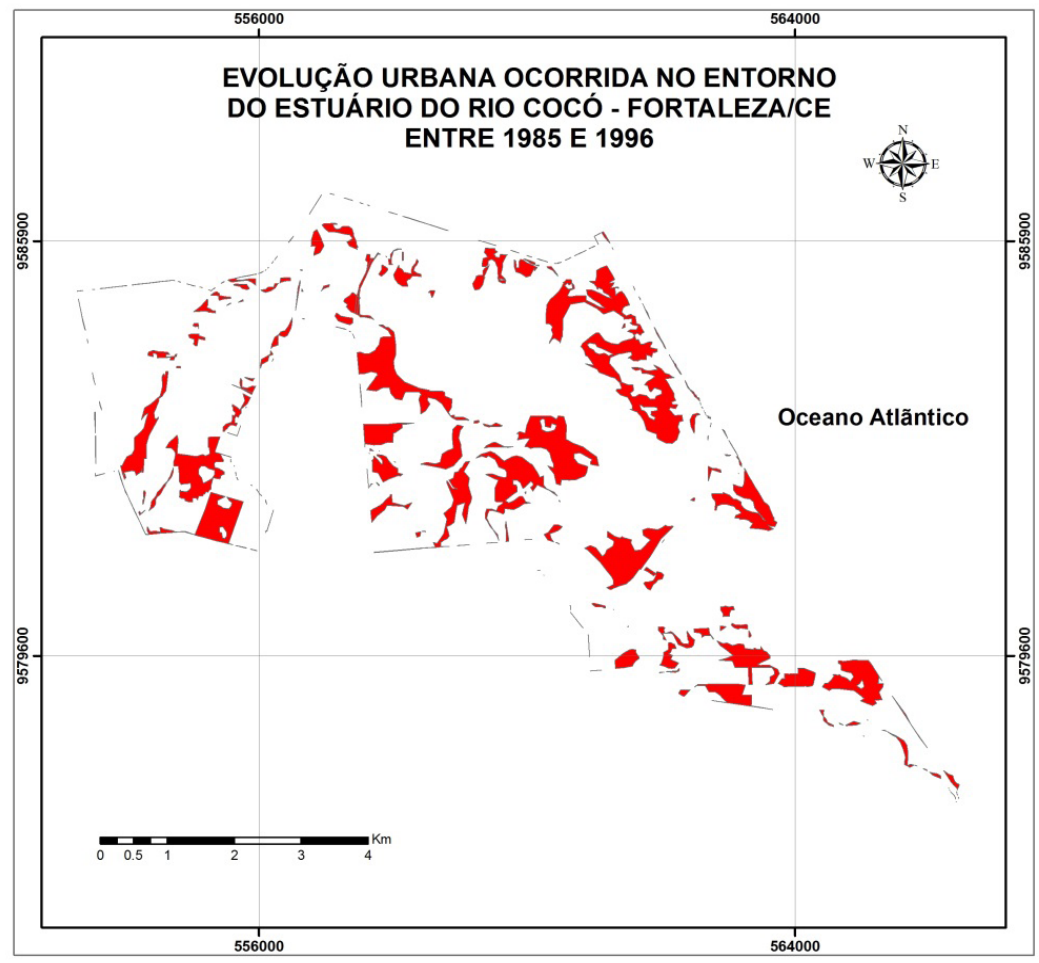

Legenda

Area Urbana

Projeção UTM

Datum: SAD69 - 24S
Geografia Ensino \& Pesquisa, v. 17, n.3, p. 153-174, set./dez. 2013

Análise da evolução urbana no entorno do estuário do Rio Cocó - Fortaleza/Ceará...

Fonte: elaboração dos autores. 
Figura 16 - Mapa contendo acréscimo de área urbana no período entre 1996 e 2007.

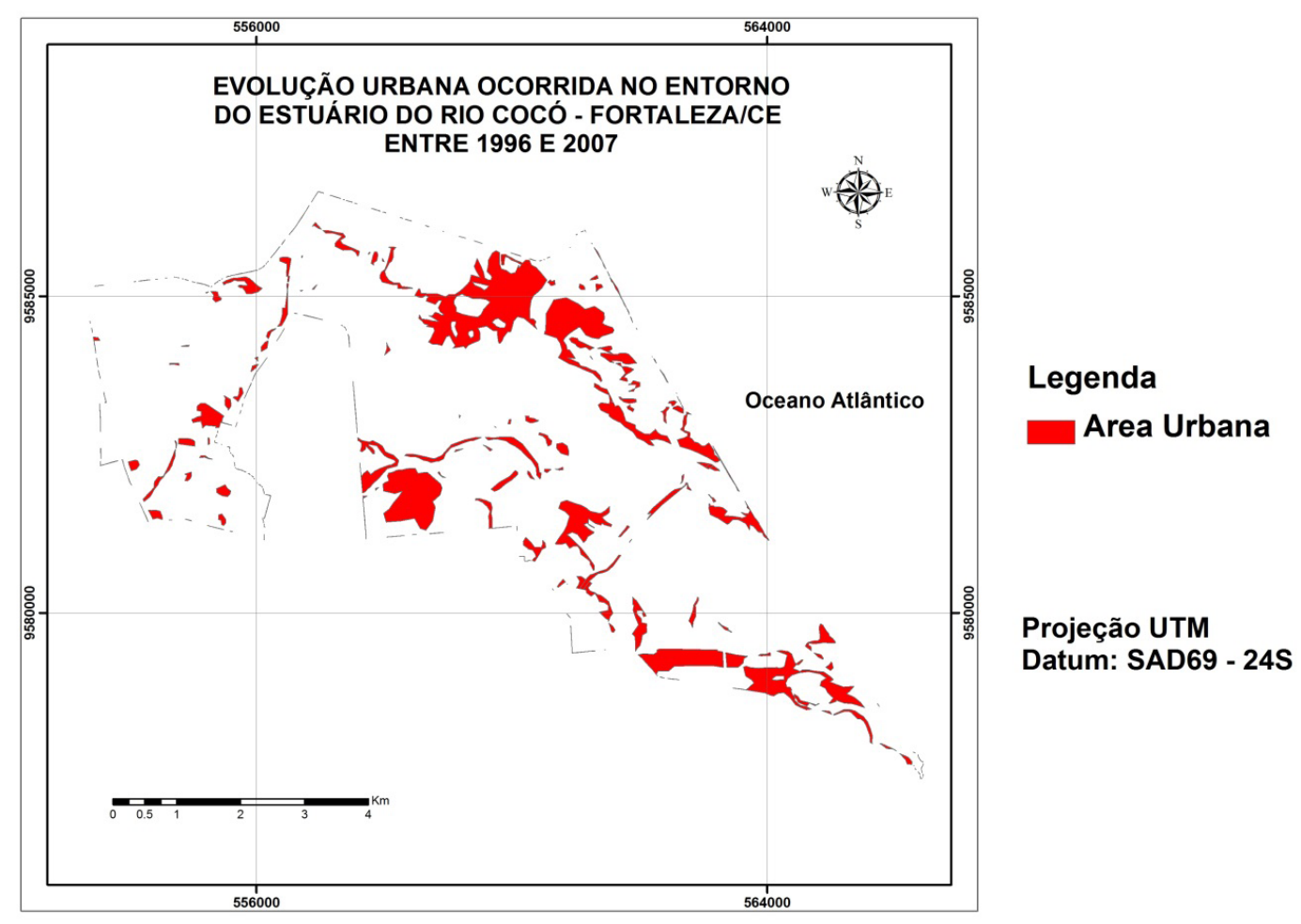

Fonte: elaboração dos autores.

Ao longo dos 22 anos analisados (1985-2007) a Área Urbana passou de 15,44 km² para 25,13 $\mathrm{Km}^{2}$, um aumento de 9,69 $\mathrm{Km}^{2}$ na malha urbana. Conforme pode ser observado no Figura 17, do total da área urbana ampliada, o primeiro período (1985-1996) representou 60,37\% $\left(5,85 \mathrm{Km}^{2}\right)$ enquanto o período posterior (1996-2007) totalizou 39,63\% (3.84 $\left.\mathrm{Km}^{2}\right)$.

Figura 17 - Percentuais de crescimento da área urbana verificado nos períodos 1985/1996 e 1996/2007.

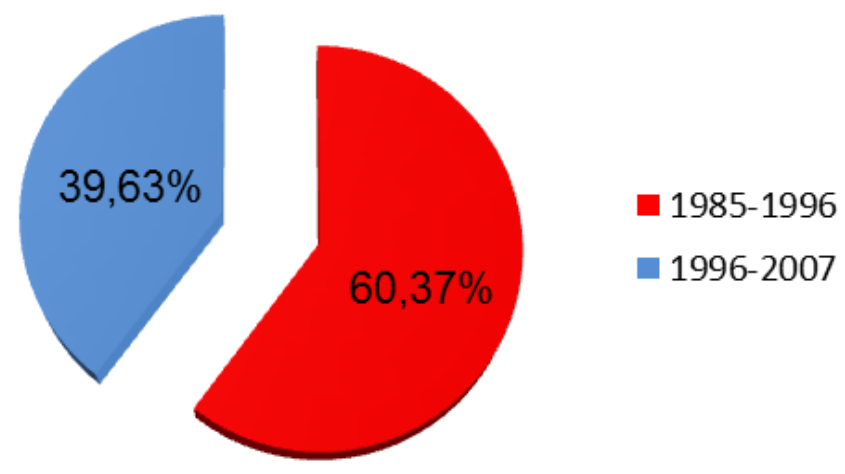

Fonte: elaboração dos autores.

Essa diferença pode ser explicada pelo fato de no período entre 1985 e 1996 ter ocorrido intervenções mais significativas por parte do poder público na área (conjuntos habitacionais, avenidas, etc.), ao mesmo tempo em que se dava a ampliação do setor de comércio e serviços, que atraia mais moradores para o local. No período seguinte (1996-2007) o crescimento da malha urbana foi limitado pela redução dos espaços passíveis de ocupação e pela valorização das terras em alguns bairros da área de estudo. Aliado a esses fatores, soma-se a criação do Parque Ecológico do Cocó em 1989, e posterior ampliação em 1993, que garantiu, através dos órgãos ambientais, um maior controle e monitoramento, embora deficitários, da expansão urbana dentro de seus limites.

Geografia Ensino \& Pesquisa, v. 17, n.3, p. 153-174, set./dez. 2013.

Freire, E. V.; Gomes, D. D. M.; Sabadia, J. A. B., Duarte, C. R.; Souto, M. V. S. 
Associado à evolução urbana e ao crescimento populacional vem ocorrendo os mais variados impactos negativos ao meio ambiente e a dinâmica do Rio Cocó.

É comum nas imediações do estuário o descarte de lixo e entulho de construção (Figura 18), mesmo havendo coleta domiciliar. Enquanto a fiscalização não ocorre de forma eficaz e a população não é educada para ter uma relação mais harmoniosa com o meio, o lixo verte para o rio e se transforma em obstáculos que provocam perda de eficiência do fluxo de água, dificultando o transporte sedimentar, gerando por sua vez assoreamento da calha fluvial.

Figura 18 - Descarte de lixo no entorno do Rio Cocó - Na margem esquerda, (A) Pólo de lazer na Av. Raul Barbosa, (B) Conjunto Habitacional Tasso Jereissati (março de 2011).

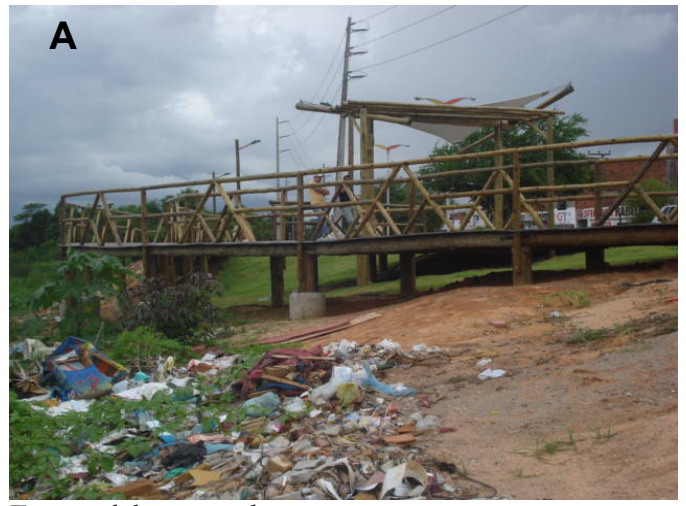

Fonte: elaboração dos autores.

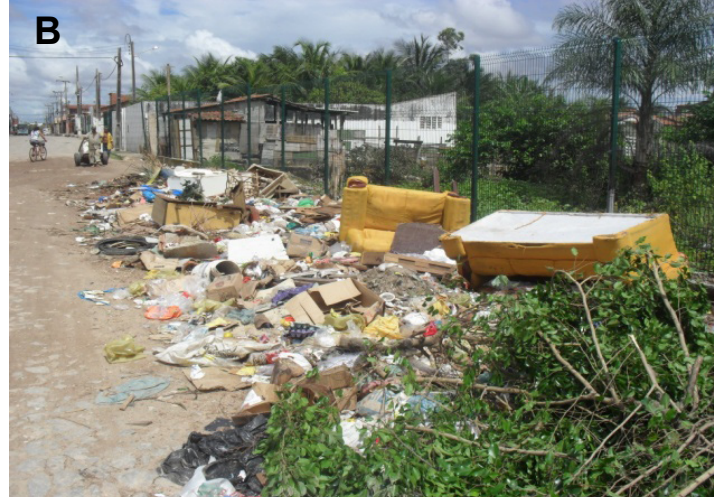

Além do lixo, outro problema crítico, é o despejo clandestino de esgotos diretamente no Rio Cocó, que ocorre, sobretudo pela carência do serviço de rede de esgoto ofertado na cidade que, segundo Fortaleza (2009), só atende 42,04\% das habitações.

Os esgotos têm origem não só nas habitações de baixa renda, mas, também, são lançados de prédios comerciais, condomínios de luxo e casas de alto padrão. Esse problema é de difícil resolução, uma vez que, após colocados os emissários de esgotos em direção ao Rio e ao mangue, fica difícil identificá-los. Muitas residências, por exemplo, utilizam as galerias de escoamento de águas pluviais para direcionar os esgotos domésticos.

Toda essa carga de poluentes tem causado graves problemas para o Rio Cocó e para o ecossistema local. Consequentemente suas águas não se encontram em condições de balneabilidade, sendo comum no seu entorno doenças de veiculação hídrica.

O Rio encontra-se eutrofizado e é marcante a presença de aguapés em seu espelho d'água (Figura 19), que se desenvolvem rapidamente em decorrência da grande quantidade de matéria orgânica lançada pelos esgotos. Tais algas, por sua vez, impedem a navegabilidade, provocam a morte da fauna aquática e dificultam o transporte sedimentar e ação da cunha salina no estuário.

Outro problema muito comum na área de estudo é o aterramento de lagoas e alagadiços com entulho para ampliação da área edificável, como pode ser observado na Figura 20. A prática do aterramento no decorrer dos anos vem produzindo o chamado efeito borda, onde os alagadiços e o mangue cedem espaço a expansão urbana e às ocupações irregulares que

Geografia Ensino \& Pesquisa, v. 17, n.3, p. $153-174$, set./dez. 2013

Análise da evolução urbana no entorno do estuário do Rio Cocó - Fortaleza/Ceará... convergem da periferia para o centro do Parque. Grandes extensões de mangue foram e estão sendo aterrados para construções de casas, condomínios, prédios comerciais e estradas.

O extrativismo vegetal, realizado pela população ribeirinha, contribui para agravar o quadro de degradação local visto que ao suprimir a cobertura vegetal o solo fica exposto à ação dos agentes erosivos aumentado o fluxo de sedimentos em direção ao rio. 
Figura 19 - Eutrofização do Rio Cocó no Bairro Aerolândia (março de 2011).

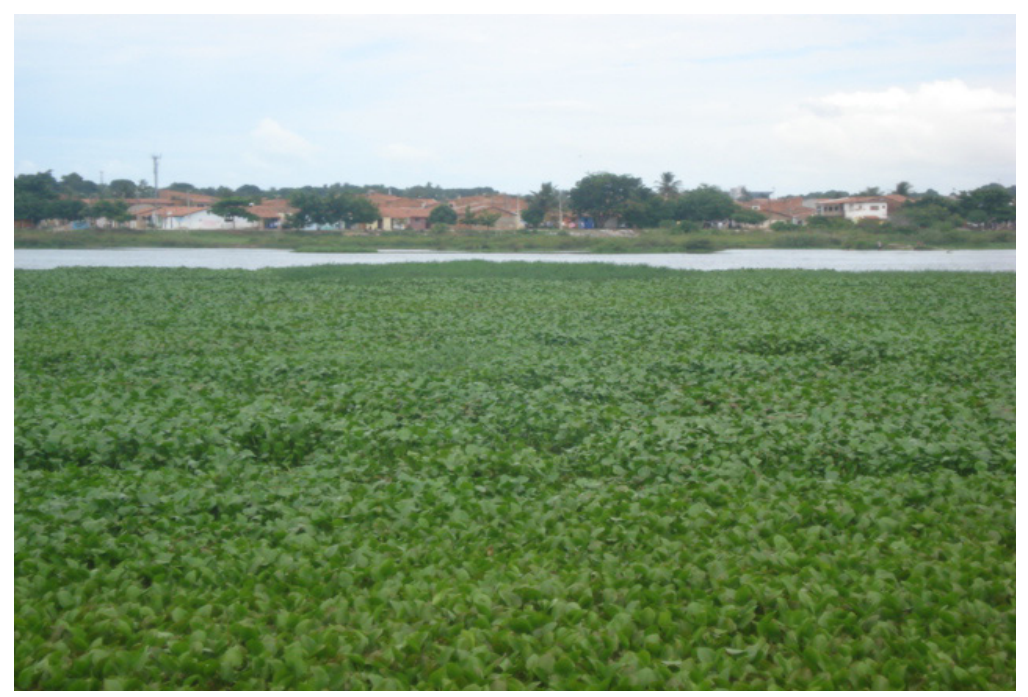

Fonte: elaboração dos autores.

Figura 20 - Eutrofização do Rio Cocó no Bairro Aerolândia (março de 2011).
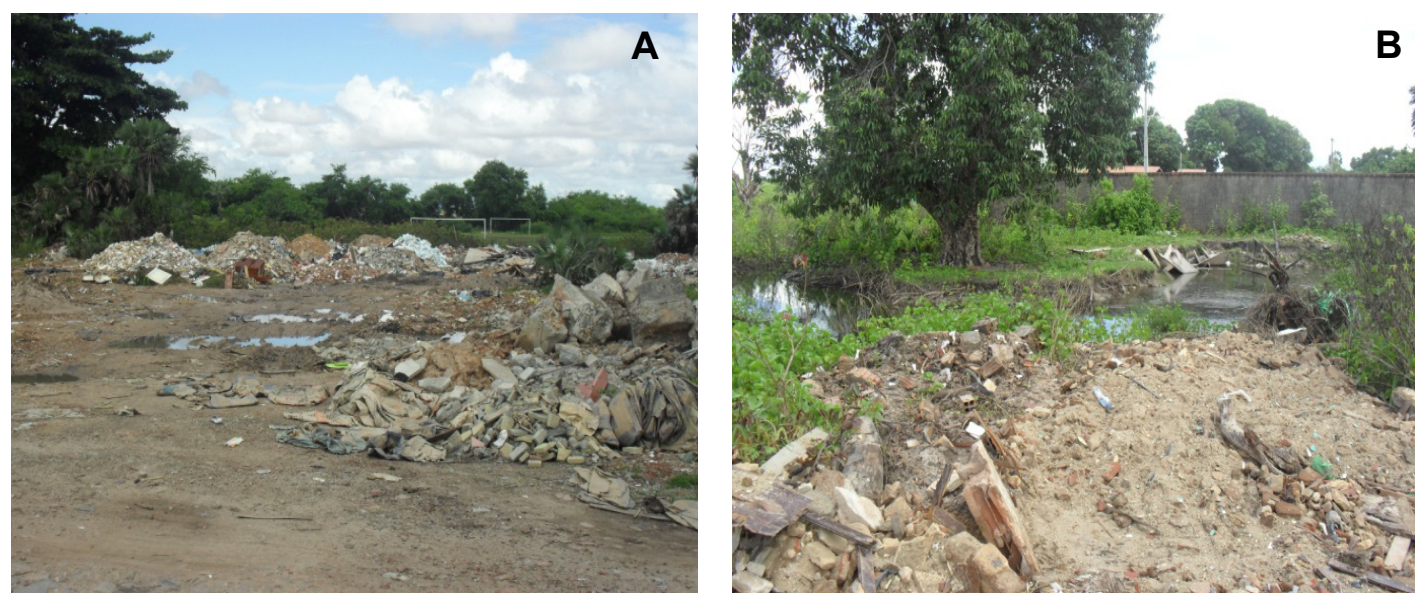

Fonte: elaboração dos autores.

A população de baixa renda tem como uma de suas principais fontes de renda e, muitas vezes, como única fonte de energia para o preparo de alimentos, o carvão vegetal, obtido através da derrubada e queima de árvores do mangue (Figura 21).

Além de tal ação predatória, é comum a produção de fogueiras por determinadas pessoas para preparação de alimentos na região, tornando propício a deflagração de incêndios no Parque, como o que foi verificado entre os dia 15 e 18 de novembro de 2010, que conforme Moscoso et al (2010), resultou na queima de pelo menos 10 hectares de vegetação.

Conforme o PDPFor (2009), no zoneamento ambiental de Fortaleza, o Parque Ecológico do Cocó faz parte da Zona de Preservação Ambiental I (faixa de preservação permanente dos recursos hídricos), sendo permitido apenas o uso indireto dos recursos naturais presentes ali. $\mathrm{O}$ uso indireto é definido como aquele que não envolve consumo, coleta ou destruição desses recursos.

Os problemas que ocorrem no Parque são de difícil identificação tendo em vista o baixo efetivo de homens para fiscalizar toda área. Segundo Moscoso et al (2010), para fiscalizar o referido Parque a CPMA dispõe de setenta homens armados distribuídos em viaturas, barcos, motos e bicicletas. Considerando a extensão do Parque de 1.155 hectares, cada polícial deverá fiscalizar uma área de 16,5 hectares. Todavia, como informou o tenente-coronel da CPMA Jonh Roseveelt Rogério Alencar, a Companhia é responsável apenas pelo trecho do Parque que compreendem as avenidas Sebastião de

Geografia Ensino \& Pesquisa, v. 17, n.3, p. 153-174, set./dez. 2013

Freire, E. V.; Gomes, D. D. M.; Sabadia, J. A. B., Duarte, C. R.; Souto, M. V. S. 
Abreu e a Murilo Borges. Sendo de sua competência a fiscalização das trilhas, e a orientação quanto a proibição do uso cigarros, de se fazer fogueira, e da abertura de novas trilhas.

Essa declaração aponta pra fragilidade da fiscalização que não ocorre em toda a extenção do Parque e favorece as constantes intervenções nos trechos não mo nitadorados.

Figura 21 - Forno improvisado para a queima de vegetação de mangue para produção de carvão, no bairro Edson Queiroz (julho de 2011).

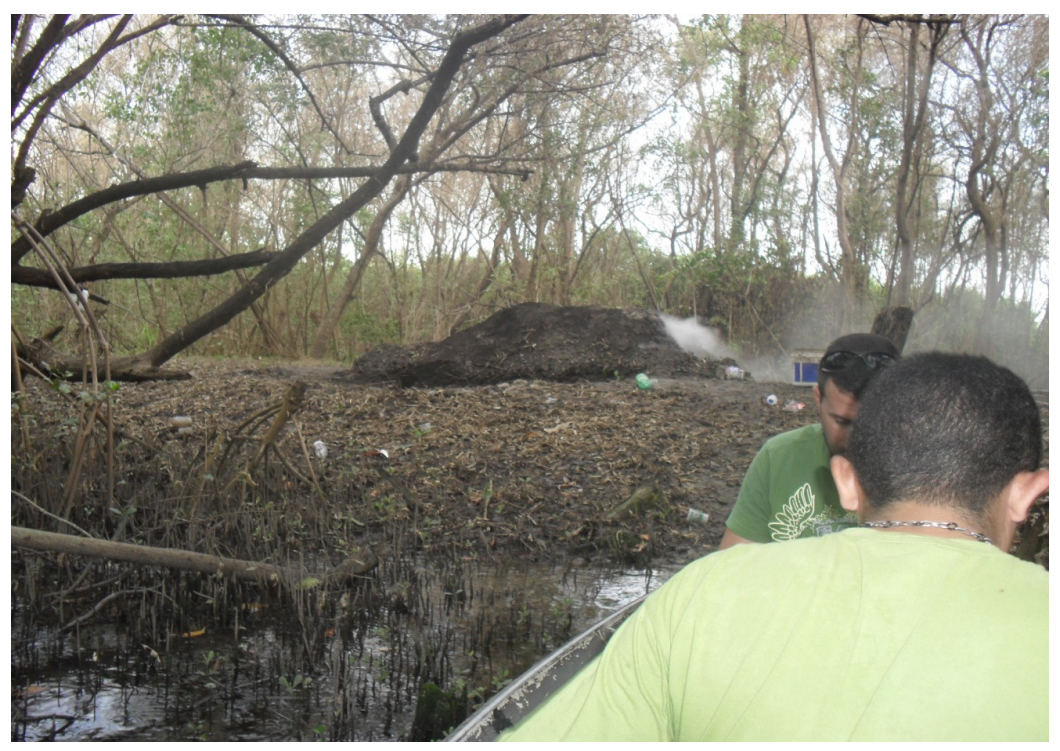

Fonte: elaboração dos autores.

\section{Conclusões/considerações finais}

Através da análise multitemporal realizada a partir das imagens Landsat-5 de 1985, 1996 e 2007 foi possível constatar a evolução urbana ocorrida nos bairros localizados no entorno do estuário do Rio Cocó no decorrer de 22 anos. Pôde ser observado ao longo do período analisado, que entre as 09 unidades de uso e cobertura do solo mapeadas (Área Urbana; Rio; Vegetação Natural; Planície Hipersalina; Lagoas e alagadiços; Dunas; Faixa de Praia; lagoas Interdunares Intermitentes; Bancos de Areia), a única que apresentou crescimento foi a Área Urbana, com um incremento de 21,44\% $\left(9,69 \mathrm{Km}^{2}\right)$.

Considerando a área urbana acrescida nesses 22 anos, o período compreendido entre 1985 e 1996 representou 60,37\% (5,85 $\left.\mathrm{km}^{2}\right)$ da expansão urbana, enquanto o intervalo entre 1996 e 2007 representou 39,63\% (3,84 $\left.\mathrm{Km}^{2}\right)$ do total $\left(9,69 \mathrm{Km}^{2}\right)$. Isso se explica pelo fato de no primeiro período ter havido intervenções mais significativas por parte do poder público através de obras de infraestrutura que, associadas à dinamização do setor de comércio e serviços, atraiu mais moradores para área. Enquanto no período seguinte, foi observada uma redução gradativa das áreas passíveis de ocupação e uma grande valorização da terra em muitos bairros da região, reduzindo, também, a taxa de expansão da malha urbana.

Associados a urbanização foram constatados a partir das atividades de campo os mais variados

Geografia Ensino \& Pesquisa, v. 17, n.3, p. $153-174$, set./dez. 2013

Análise da evolução urbana no entorno do estuário do Rio Cocó - Fortaleza/Ceará...

172 I ISSN 2236-4994 impactos negativos ao meio ambiente e a dinâmica do rio, como: descarte de lixo e entulho, despejos de esgotos, aterramentos do mangue e alagadiços, assoreamento do rio, desmatamento, incêndios etc.

Os resultados apresentados apontam para a necessidade de um monitoramento sistemático da expansão urbana na área; para identificação e controle das cargas poluentes de origem residencial e comercial; para o fomento da educação ambiental; para a ampliação do efetivo de policiais na fiscalização do Parque Ecológico do Cocó e para a sua adequação ao Sistema Nacional de Unidade de Conservação - SNUC, conforme a Lei Federal no 9985 de julho de 2000. 


\section{Agradecimentos}

Ao Curso de Pós-Graduação em Geologia da Universidade Federal do Ceará, a professora Dra. Lúcia Maria Silveira Mendes, ao Professor Dr. Antônio Jeovah de Andrade Meireles e ao Professor Dr. Michael Vandesteen Silva Souto.

\section{Referências}

BRASIL, Instituto Nacional de Pesquisas Espaciais (INPE). SPRING 5.0.6. São José dos Campos, 2005. Disponível em: http://www.dpi.inpe.br/SPRING/portugues/download.phpl. Acesso em Janeiro, 2011.

Instituto Nacional de Pesquisas Espaciais (INPE). TERRAVIEW 3.3.0. São José dos Campos, 2005. Disponível em: http://www.dpi.inpe.br/terraview/portugues/download.phpl. Acesso em Janeiro, 2011.

Instituto Nacional de Pesquisas Espaciais (INPE). Catálogo de Imagens. São José dos Campos, 2005. Disponível em: http://www.dgi.inpe.br/CDSR/. Acesso em abril, 2011.

CEARÁ. Sistema de Informações dos Recursos Hídricos do Ceará (SIRH-CE). Disponível em: <http://atlas.srh.ce.gov.br/>. Acesso em julho de 2011.

CUNHA, S.B. Geomorfologia fluvial. In: GUERRA, Antonio José Teixeira; CUNHA, Sandra Baptista da. Geomorfologia - Uma atualização de bases e conceitos. 6a ed. Rio de Janeiro: Bertrand Brasil, 2005. $211-252$.

FLORENZANO, T. G. Imagens de satélite para estudos ambientais. São Paulo: Oficina de textos, 2002. . Sensoriamento Remoto para geomorfologia. In: FLORENZANO, T.G. (org.). Geomorfologia: conceitos e tecnologias atuais. São Paulo: Oficina de textos, 2008. 36 -71.

FREIRES, E.V. Detecção de mudanças na cobertura vegetal no município de Maracanaú/Ce, através de imagens Landsat-5 e SIG. 2009, 81p. Monografia (Especialização em geoprocessamento aplicado a análise ambiental e recursos hídricos). Universidade Estadual do Ceará. Fortaleza, 2009.

GOMES, D. D. M. ; MENDES, L. M. S. ; Medeiros, C. N. de ; Veríssimo, C. U. V. Análise multitemporal do processo de degradação da vegetação da Bacia Hidrográfica do Rio Jaibaras no Estado do Ceará. Geografia. Ensino \& Pesquisa (UFSM), v. 15, p. 41-62, 2011.

JACINTHO, Luis Roberto de Campos. Geoprocessamento e sensoriamento remoto como ferramentas na gestão ambiental de unidades de conservação: o caso da Área de Proteção Ambiental (APA) do Capivari - Monos, São Paulo - SP. 2003. 110p. Dissertação (Mestrado em recursos minerais e hidrogeologia) - Universidade de São Paulo, São Paulo, 2003.

JUNIOR, A.B.M.; SOUSA, C.J. da S.. Detecção de mudanças na cobertura vegetal, através da subtração de imagem NDVI, no Parque Estadual do Bacanga - São Luis - MA. In: Simpósio Brasileiro de Sensoriamento Remoto, 13., 2007, Florianópolis. Anais... São José dos Campos. INPE, 2007. p 4013-4020.

MOSCOSO, L; PEIXOTO, M.; PETRUCCI, J. Incêndio no Cocó foi criminoso: extensão da área dificulta fiscalização efetiva. Diário do Nordeste, Fortaleza, p.11, 18 nov. 2010.

NASA - National Aeronautics and Space Administration. GeoCover LANDSAT mosaics. California, 2004. ETM+/LANDSAT-7.Tile: S-24-00_2000. Disponível em: http://www.zulu.ssc.nasa.gov/mrsid/ mrsid.pl. Acesso em: abril, 2010.

PDPFor, Plano Diretor Participativo de Fortaleza. Fortaleza: Prefeitura municipal de Fortaleza, 2009. 520p.

Geografia Ensino \& Pesquisa, v. 17, n.3, p. 153-174, set./dez. 2013.

Freire, E. V.; Gomes, D. D. M.; Sabadia, J. A. B., Duarte, C. R.; Souto, M. V. S.

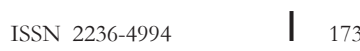


SILVA, Jorge Xavier da. Geoprocessamento para a análise ambiental. Rio de Janeiro: J. Xavier Silva, 2001.

SILVA, Carlos Salvato. A degradação do manguezal do Rio Cocó: uma análise das causas. 2003, 238p. Dissertação (Mestrado Acadêmico em Geografia) - Universidade Estadual do Ceará. Fortaleza, 2003.

\section{Correspondência:}

Eduardo Viana Freires - Escola Municipal de Ensino Fundamental Braz Ribeiro da Silva. Rua 21 de Abril, 291, Bairro Boa Vista. Maracanaú - CE, CEP 60900030.

E-mail: eduardovina_geo@hotmail.com

Recebido em 11 de março de 2013.

Revisado pelo autor em 13 de seetembro de 2013.

Aceito para publicação em 21 de novembro de 2013. 